\title{
Towards a translational model of panic attack
}

\author{
Luiz Carlos Schenberg \\ Universidade do Espirito Santo, Brazil
}

\begin{abstract}
About 20 years ago, Deakin and Graeff proposed that whereas generalized anxiety disorder is produced by the overactivity of 5-HT excitatory projections from dorsal raphe nucleus to the areas of prefrontal cortex and amygdala which process distal threat, panic attacks are a dysfunction of 5-HT inhibitory projections from dorsal raphe nucleus to the dorsal periaqueductal gray matter, thereby releasing the responses to proximal threat, innate fear or anoxia. Besides, they suggested that the decrease in 5-HT1A neurotransmission in the hippocampus results in learned helplessness and depression. Accordingly, the Deakin Graeff hypothesis provided a unified frame to the widespread use of 5-HT selective reuptake inhibitors in generalized anxiety, panic disorder and depression. Competitor hypotheses implicate panic attacks with the abnormal functioning of locus coeruleus, basolateral amygdala, dorsomedial hypothalamus or an as-yet-unknown suffocation alarm system. Conversely, cognitive psychologists suggest that panic attacks result from the catastrophic (cortical) interpretation of bodily symptoms. In any event, translational models of panic attack are expected to reproduce the main features of clinical panic, namely, the patient's higher sensitivity to both lactate and $\mathrm{CO} 2$, the drug specific sensitivity, the lack of stress hormone responses during panic attacks, the higher vulnerability of women and the high comorbidity with agoraphobia, major depression and childhood separation anxiety. Therefore, here we review the main steps in the experimental approach to anxiety disorders which are paving the route towards a translational model of panic attack. Keywords: Panic, Anxiety, Stress, Suffocation, Serotonin, Periaqueductal Gray Matter
\end{abstract}

Received 3 May 2010; received in revised form 26 June 2010; accepted 26 June 2010. Available on line 26 June 2010

\section{A short story of panic disorder}

The foundations of the modern nosology of anxiety disorders were laid down by Sigmund Freud's original classification of 'anxiety neuroses' (Angstneuroses) (Freud, 1896). In this early study, Freud attempted to distinguish anxiety disorders from 'melancholia' (major depression, MD) and a number of ill-defined psychiatric conditions which were at time subsumed under the label of 'neurasthenias'. Remarkably, Freud discerned two major syndromes of anxiety, i.e., the 'anxious expectation' or 'apprehension', which he considered the most essential form of anxiety disorder, and the less frequent 'attack of anxiety'. According to Freud, whereas the anxious expectation was 'a quantum of freely floating anxiety which controls the choice of ideas by expectation', anxiety attacks consisted in the sudden irruption of anxiety 'into consciousness without being aroused by the issue of any idea'. Freud emphasized that anxiety attacks could manifest either as 'the anxious feeling alone' or the combination of

Luiz Carlos Schenberg, Associate Professor, Department of Physiological Sciences, Federal University of Espírito Santo, Vitória, ES; Brazil. Correspondence regarding this article should be directed to: Dr. L. C. Schenberg, Departamento de Ciências Fisiológicas, CCS - UFES, Av. Marechal Campos 1468 (Maruípe), 29043-125, Vitória-ES, Brazil. Phone: +55-27-3335-7332. Fax: +55-27-3335-7340. E-mail: schenber@gmail.com.br this feeling with the nearest interpretation of the termination of life, such as the idea of sudden death or threatening insanity'. As well, anxiety attacks could be associated to 'some paresthesia ... [or] a disturbance of one or many somatic functions, such as respiration, cardiac activity, vasomotor innervation, and glandular activity'. Remarkably, Freud pointed out that patients suffering from anxiety attacks 'put the feeling of anxiety to the background or [describe it] rather vaguely ... as feeling badly, uncomfortably, etc', an observation corroborated by present-day psychiatrists. Freud was also aware about the high comorbidity of panic attacks and agoraphobia and linked the latter condition to a 'locomotion disorder' caused by the presence of dizziness during panic attacks. (pp. 87-89) Freud's descriptions of 'anxious expectation' and 'anxiety attack' were very much the same of nowadays respective diagnoses of generalized anxiety disorder (GAD) and panic disorder (PD). However, it would take almost a century before the inclusion of PD as a definite psychiatric illness in the Diagnostic and Statistical Manual of the American Psychiatric Association (DSM-III, APA, 1980).

Presumably, Freud's clinical heritage was in some measure lost following the profound divorce of psychoanalysis from medicine. Consequently, anxiety disorders continued to be vaguely diagnosed as 'neurasthenias' up to the middle of the last century. Moreover, PD received a bewildering wealth of names 
including neurocirculatory asthenia, vasomotor neurosis, nervous tachycardia, effort syndrome, Da Costa's syndrome, irritable heart, soldier heart and others (Pitts \& McClure, 1967). This scenario begun to undergo a profound change following the publication of Donald Klein's influential study showing that GAD and PD were treated by different classes of drugs (Klein, 1964). Klein observed that whereas the 'anxious expectation' responded to the current time anxiolytics (barbiturates, meprobamate, chlordiazepoxide and low doses of phenothiazines), panic attacks were only treated by the chronic administration of the tricyclic antidepressant (TCA), imipramine.

Around the same time, Pitts and McClure (1967) showed that panic attacks had 'physiological markers' insofar that they could be precipitated by intravenous infusions of $.5 \mathrm{M}$ sodium lactate in patients prone to spontaneous panic but not in normal volunteers. Further studies provided ample evidence of the panicogenic properties of sodium lactate, but also of $\mathrm{CO}_{2}$ and brain acting drugs such as yohimbine, cholecystokinin (CCK), flumazenil, $\beta$-carboline, caffeine, etc (for review, see Graeff, Garcia-Leal, Del-Ben, \& Guimarães, 2005). The demonstration of the existence of physiological markers and drug-specific treatments of PD suggested that panic attacks were the outcome of a defective brain circuit discharging maladaptively.

The next breakthrough came a few years after the inclusion of PD in the DSM-III (APA, 1980). Indeed, the demonstration that clinical and lactate-induced panics do not activate the hypothalamus-pituitaryadrenal (HPA) axis was a remarkable finding inasmuch as it differentiated clinical panic from stress-like reactions and common fear (Hollander et al., 1989a, 1989b, 1989c; Levin et al., 1987; Liebowitz et al., 1985; Woods, Charney, Goodman, \& Heninger, 1988; Woods, Charney, McPherson, Gradman, \& Heninger, 1987; ). These studies also brought into question the cognitive hypothesis which equated clinical panic to the fear produced by the catastrophic evaluation of bodily symptoms (Clark et al., 1997; Ehlers et al., 1986; Margraf, Ehlers, \& Roth, 1986). The cognitive hypotheses were also challenged by studies showing that panic patients do not endorse somatic symptoms indiscriminately (Goetz et al., 1989).

These and other findings led Klein (1993) to suggest that clinical panic is bound to the fear of suffocation, of which dyspnoea (but not hyperpnoea) is the leading feature. According to Klein's hypothesis, panic attacks are the outcome of the misfiring of an evolved suffocation alarm system. This results in a sudden respiratory distress followed by a brief hyperventilation, panic, and the urge to flee. Klein (1993) argued that the suffocation false alarm hypothesis (SFA) is an explanation both sufficient and consistent of $\mathrm{CO}_{2}$ and lactate hypersensitivity of panic patients, of the occurrence of panic attacks during relaxation and sleep, of the increased frequency of panic attacks in the late luteal phase dysphoric disorder (LLPDD) and, conversely, its reduction in pregnancy, delivery and lactation. As a matter of fact, $\mathrm{CO}_{2}$ and lactate-induced panic attacks remains the best model of clinical panic insofar that they are not precipitated in healthy subjects (Klein, 1993; Pitts \& McClure, 1967) or patients suffering from obsessive-compulsive disorder (as cited by Griez \& Schruers, 1998) and social phobia (Liebowitz et al., 1985b). Also, whereas the panic attacks produced by infusion of lactate or inhalation of $\mathrm{CO}_{2}$ are blocked by chronic treatment with TCA (Liebowitz et al., 1985a; Rifkin, Klein, Dillon, \& Levitt, 1981; Woods, Charney, Delgado, \& Heninger, 1990; Yeragani et al., 1988), panics induced by $\beta$-carboline (Dorow, Horowski, Paschelke, \& Amin, 1983) and yohimbine are not (Klein, 1993). The SFA hypothesis is also consistent with the high comorbidity of panic and respiratory diseases (Preter \& Klein, 2008; Shavitt, Gentil, \& Mandetta, 1992). However, patients with GAD and, more markedly, LLPDD are also highly sensitive to $\mathrm{CO}_{2}$ (Kent et al., 2001; Lapierre, Knott, \& Gray, 1984).

Following the advent of DSM-III (APA, 1980), experimental researchers became gradually aware about the similarity of panic attacks with the defensive behaviors and aversive emotions long known to be produced by electrical stimulation of the dorsal half of periaqueductal gray matter (DPAG) of animals (Fernandez de Molina \& Hunsperger, 1962) and humans (Nashold, Wilson, \& Slaughter, 1969), respectively. At the same time, the serotonin (5-HT) selective reuptake inhibitors (SSRI) begun to be widely prescribed for MD, GAD and PD. Therefore, Deakin and Graeff (1991) put forward a daring hypothesis according to which the 5-HT ascending systems of the brain evolved as a mechanism concerned with adaptive responses to aversive events. Briefly, the Deakin-Graeff hypothesis (DGH) suggests that whereas GAD is produced by the overactivity of 5-HT excitatory projections from dorsal raphe nucleus (DRN) to regions of prefrontal cortex (PFC), amygdala and hypothalamus which process distal threats, panic attacks would be the outcome of the malfunctioning of 5-HT inhibitory projections from that nucleus to the DPAG (Figure 1), thereby releasing the defensive responses to innate fear, proximal threat and anoxia. In addition, they proposed that 5-HT efferents from median raphe nucleus (MnR) to the hippocampus would be the substrate of a 'behavior resilience system' that uncouples stressful events from daily life routines (Figure 1). Reduction of 5- $\mathrm{HT}_{1 \mathrm{~A}}$ neurotransmission of hippocampus would result in learned helplessness and depression. Besides providing a unified frame to the widespread use of SSRIs in GAD, PD and MD, the DGH suggested that DRN 5-HT efferents facilitate avoidance during anticipation of threat at amygdala while restrain the fight/flight components of proximal 
defense system at DPAG. Finally, the DGH assumes that conflictive behaviors are processed via 5 -HT and dopamine receptors of ventral striatum which mediate avoidance and approach behaviors, respectively (Figure 1). The latter proposal was a manifest rupture with Gray's well-known model which credited anxieties of conflict, frustration and novelty to the activation of classical limbic pathways connecting the medial septum to the ventral hippocampus (Gray, 1976; Gray, 1982; Gray \& McNaughton, 2000).
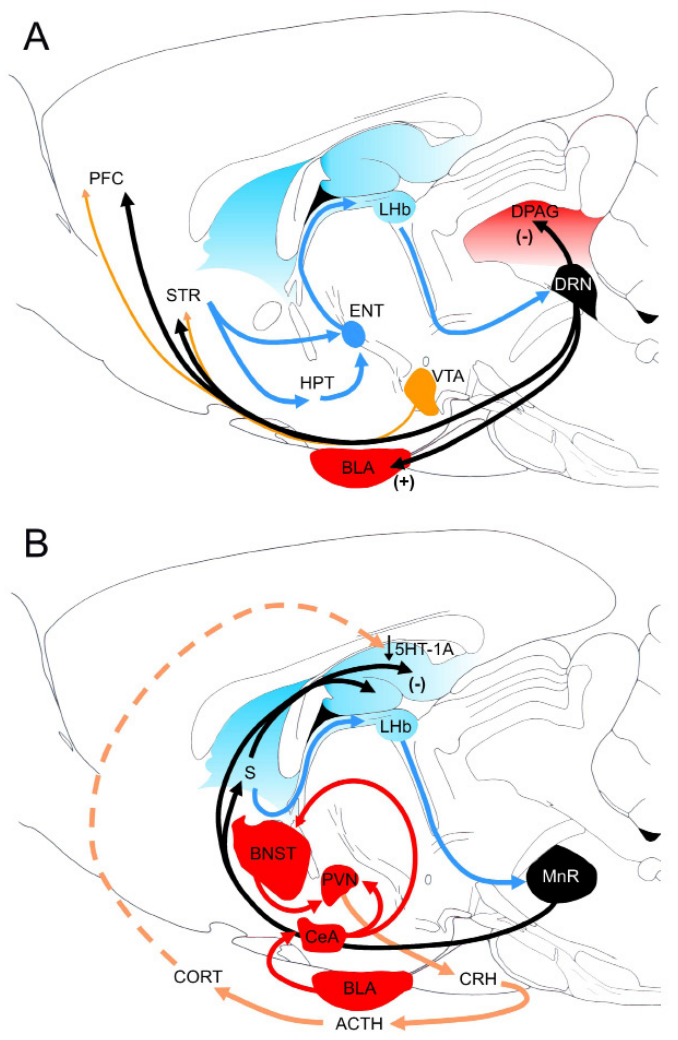

Figure 1. A rat-brain model of the Deakin-Graeff Hypothesis: A) Deakin and Graeff (1991) suggested that whereas the generalized anxiety disorder is produced by the overactivity of 5-HT (black arrows) excitatory projections from dorsal raphe nucleus (DRN) to areas of prefrontal cortex (PFC) and amygdala (BLA) which process distal threat, panic attacks are a dysfunction of 5-HT inhibitory projections from that nucleus to the dorsal periaqueductal gray matter (DPAG), thereby releasing the responses to proximal threat, innate fear or anoxia. In turn, conflict anxiety is the outcome of the simultaneous activity of 5-HT projections from DRN and dopamine projections (thin gray arrows) from ventral tegmental area (VTA) targeting the striatum (STR) and mediating avoidance and approach behaviors, respectively. B) Deakin and Graeff (1991) also proposed that 5-HT efferents from median raphe nucleus $(\mathrm{MnR})$ to the hippocampus are the substrate of a 'behavior resilience system' that uncouples stressful events from daily life routines. Stress increased levels of glucocorticoids (CORT) would downregulate the 5-HT receptors of hippocampus, thereby leading to learned helplessness and depression. Note the central place of lateral habenula $(\mathrm{LHb})$ in the regulation of DRN and MnR activities. Other abbreviations: BLA - basolateral amygdala, BNST - bed nucleus of stria terminalis, CeA - central amygdala, CRH - corticotrophin releasing hormone, HPT hypothalamus, ENT - nucleus entopeduncularis (internal pallidum), PVN - paraventricular nucleus of hypothalamus, $\mathrm{S}$ - septum.
Nevertheless, PD patients also complain of 'anticipatory anxiety', i.e., the expectant fear of lack of support when overwhelmed by a panic attack. As a matter of fact, because this condition very often aggravates in a disabling agoraphobia, the DSM-IV does not consider agoraphobia as an anxiety disorder on its own. Clinical evidence also suggests that sudden loss, bereavement and childhood separation anxiety are antecedents of 'spontaneous' panic attacks (Klein \& Fink, 1962). The comorbidity of PD and childhood separation anxiety disorder is also supported by the proven effectiveness of imipramine in the latter condition (Bernstein et al., 2000; Gittelman-Klein \& Klein, 1973). Moreover, although the agoraphobia was usually explained by the conditioned generalization of fear of having panic attacks in public places, crises rarely occur when patients go out escorted by relatives. The urge of an integrative explanation of these facts led Preter and Klein (2008) to extend the SFA. Thus, because the opioid systems have prominent roles in both breathing and separation distress, Preter and Klein (2008) suggested that panic attacks are produced by an episodic dysfunction of opioidergic systems which decreases the threshold of suffocation alarm system. This possibility was supported by a recent study showing that infusions of lactate in naloxonetreated healthy volunteers produce respiratory distress and feelings which mimic those of panic attacks either spontaneous or induced by lactate (Preter et al., 2010).

Therefore, although most models based on animal studies equate panic to the defensive behaviors of preys to a proximal threat (Blanchard, Griebel, \& Blanchard, 2003; Deakin \& Graeff, 1991; Mobbs et al., 2007), the development of a translational model of clinical panic is expected to reproduce the key features of PD, namely, drug treatment specificity, lactate and $\mathrm{CO}_{2}$ hypersensitivity, lack of stress-hormone responses, the higher vulnerability of female sex and the high comorbidity with depression and separation anxiety, among other conditions. Indeed, the coming DSM-V puts a major emphasis on the comorbidity of psychiatric disorders (Holden, 2010). Therefore, the present study highlights the main breakthroughs in experimental research which are setting the stage for the development of a translational model of panic attack. The review considers first the main findings leading to the development of DGH and, secondly, the eventual participation of PAG in a suffocation alarm system SFA. A reconciling hypothesis is then proposed.

\section{Foundations of deakin-graeff hypothesis}

Because the main assumptions and implications of DGH have been intensively debated since its publication 20 years ago (Graeff, 2004; Graeff \& Guimarães, 1999; Gray \& McNaughton, 2000; McNaughton \& Corr, 2004; Mobbs et al., 2007), the reader is asked to forego 
any detail in here. Moreover, the DGH proposals on the mechanisms of anxiety and panic attacks are more emphasized than the mechanisms concerned with depression disorders.

The development of models of experimental conflict in which water- and food-rewarded behaviors are suppressed by the intermittent presentation of shocks had a major impact in drug research insofar that they enabled to discriminate the anxiolytic effects of barbiturates, meprobamate and chlordiazepoxide from their own sedative effects and the sedative effects of antipsychotics and opioids (Geller, Kulack, \& Seifter, 1962). Consequently, much of the early research on the neural basis of anxiety sought to explain the disinhibitory effect of anxiolytics in experimental conflict. Most notably, the study of Graeff and Schoenfeld (1970) was a major breakthrough inasmuch as it showed that the 5-HT agonist alpha-methyltryptamine facilitated shockinduced suppression of a food-rewarded behavior, whereas the 5-HT antagonists, methysergide and bromolysergic acid, released punished behavior in pigeons (Figure 2 ). These observations were in line with contemporary studies carried out with the less specific method of 5-HT depletion by para-chlorophenylalanine (PCPA) (Geller \& Blum, 1970; Hartmann \& Geller, 1971; Robichaud \& Sledge, 1969). The role of 5-HT in punishment, behavioral inhibition and anxiety seemed thus relatively established almost four decades ago. Consequently, even the anxiolytic actions of benzodiazepines were suggested to be mediated by a reduction in the turnover of 5-HT ascending fibers controlling aversive behaviors (Wise, Berger, \& Stein, 1970, 1972, 1973) (Figure 3). Accordingly, the early models of behavioral suppression based on the cholinergic neurotransmission at the hypothalamus (Margules \& Stein, 1969a, Margules \& Stein, 1969b; Sepinwall \& Grodsky, 1969) were very soon replaced by 5-HT-based models of punishment. Yet, other authors suggested that the benzodiazepine anxiolytic effects were due to a reduction in the turnover of norepinephrine (NE) (Taylor \& Laverty, 1969).

On the other hand, the combination of operant conditioning and brain stimulation resulted in the discovery of rewarding and aversive systems of the brain (Delgado, Roberts, \& Miller, 1954; Olds \& Milner, 1954). Particularly, Olds and Olds (1963) showed that whereas the stimulation of the lateral hypothalamus (medial forebrain bundle) produced very strong approach responses, stimulation of periventricular hypothalamus and periaqueductal gray matter (PAG) yielded pure negative reinforcement regularly. Consequently, the brain aversive areas stood out as the presumptive substrates of fear and anxiety.

Mapping of brain aversive areas also provided the opportunity for a direct investigation of the role of neurotransmitters in these systems. Thus, in the mid 70 's, researchers begun to examine the effects of drugs

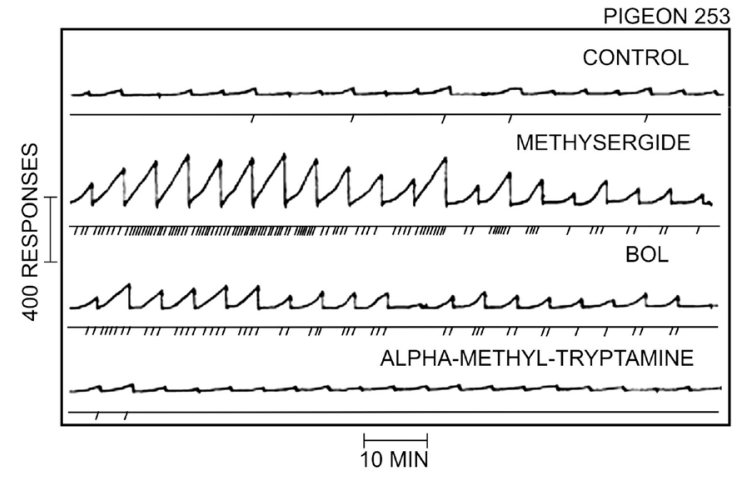

Figure 2. Effects of the 5-HT agonist alpha-methyl-tryptamine and the 5-HT antagonists methysergide and bromolysergic acid (BOL), on the punished behavior of a pigeon on a concurrent fixed-interval $(5 \mathrm{~min})$ food reinforced and fixed-ratio (30 responses) shock punishment schedule. Note the marked facilitation of punished behavior of methysergide and BOL sessions (middle recordings) as compared to the control session (top). Vertical pen deflections in event line indicate shocks applied to the pigeon (from Graeff \& Schoenfeld, 1970).

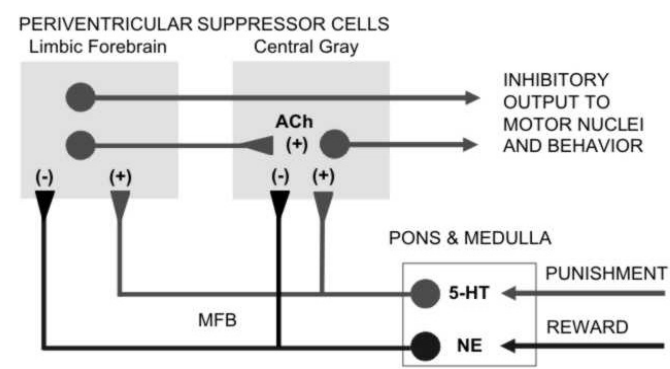

Figure 3. Diagram illustrating the presumptive roles of serotonin (5-HT) and norepinephrine (NE) in the punishment early model of Wise, Berger and Stein (1973). According to these authors, signals of positive reinforcement release behavior from cholinergic periventricular suppression cells through the activation of NE containing neurons in pons (locus coeruleus). In turn, signals of punishment increase behavioral suppression by activation of dorsal raphe and other 5-HT groups. The role of these transmitters in reward and punishment will be fully reinterpreted in the following years.

acting on 5-HT and gamma-aminobutyric acid (GABA) neurotransmission on bar-pressing escape behavior reinforced by the terminus of an electrical stimulus applied at the DPAG. Particularly, Schenberg and Graeff (1978) showed that DPAG-evoked bar-pressing escape was attenuated by peripheral administration of non-sedative doses of chlordiazepoxide $(5.6-10 \mathrm{mg} /$ $\mathrm{kg}$ ) (Figure 4). These results supported the role of DPAG in both the anxiety and the anxiolytic action of benzodiazepines.

However, DPAG-evoked escape responses were unexpectedly facilitated by the 5-HT receptor antagonists cyproheptadine and methysegide, thereby suggesting an anxiolytic action of 5-HT (Figure 4). These experiments were replicated by Clarke and File (1982), using the same 5-HT antagonists and lorazepam, and agreed with 
contemporary studies carried out with the model of 'decremental' escape in which each bar-press produced a fixed reduction in the intensity of an electrical stimulus applied to the DPAG (Kiser \& Lebovitz, 1975; Kiser, German, \& Lebovitz, 1978). Thus, whereas the DPAGevoked decremental escape was facilitated by 5-HT depletion with PCPA, it was attenuated by the 5-HT precursor 5-hydroxytryptophan (5-HTP) and the SSRI clomipramine (CLM, $15 \mathrm{mg} / \mathrm{kg}$ ) (Kiser \& Lebovitz, 1975; Kiser et al., 1978). In contrast, the administration of $15 \mathrm{mg} / \mathrm{kg}$ protriptyline, a preferential inhibitor of NE reuptake, was ineffective (Kiser et al., 1978). In keeping with the study of Simon, Le Moal and Cardo (1976), Schenberg and Graeff (1978) also showed that the stimulation of DRN had rewarding effects.

While the latter studies were at variance with prevailing views suggesting that 5 -HT mediated the behavioural effects of punishment (Graeff \& Schoenfeld, 1970; Wise, Berger, \& Stein, 1973), studies with 5-HT depletion with para-chlorophenylalanine (PCPA) or electrolytic lesion of

DOSES OF CYPROHEPTADINE IN MG/KG
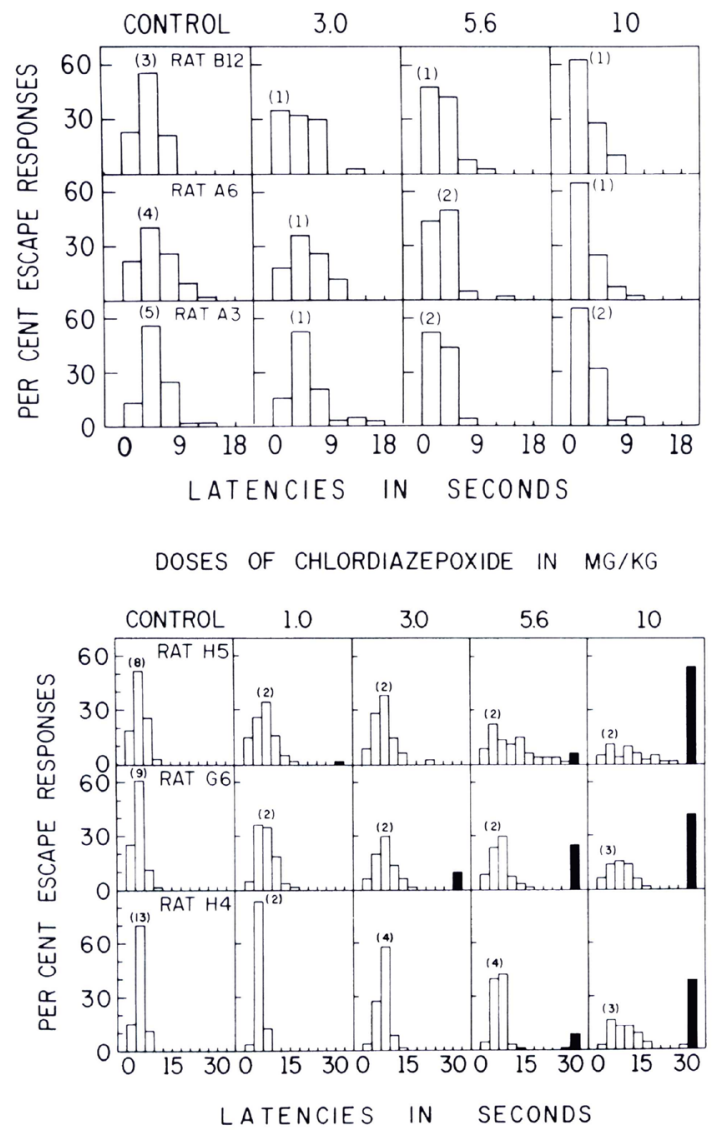

Figure 4. Opposite effects of the 5-HT antagonist cyproheptadine (upper panel) and the benzodiazepine chlordiazepoxide (lower panel) on bar-pressing escape responses from electrical stimulation of dorsal periaqueductal gray. Note the dose-dependent increase in short- or longlatency escape responses following the administration of cyproheptadine or chlordiazepoxide, respectively (from Schenberg Graeff, 1978).
5-HT neurons of MnR strongly supported the role of this transmitter in behavioral inhibition (Lorens, Sorensen, \& Yunger, 1971; Srebro \& Lorens, 1975). In addition, whereas the electrical stimulation of DRN with currents above 250 $\mu$ A produced only arousal and orientation (Jacobs, 1973), the electrical stimulation of $\mathrm{MnR}$ with much lower intensities $(40-200 \mu \mathrm{A})$ produced the suppression of food-reinforced bar-pressing behavior along with fear-like responses of crouching, dyspnoea, defecation, piloerection and teeth chattering (Graeff \& Silveira Filho, 1978). Moreover, the latter authors showed that MnR-evoked behavioral suppression was abolished by the previous administration of PCPA and restored by the 5-HT precursor 5-HTP.

As a result, Schenberg and Graeff (1978) suggested that benzodiazepine anxiolytic effects involve the concomitant inhibition of periventricular/periaqueductal and raphe/septohippocampal systems thought to mediate the behavioral inhibition of punishment (Wise, Berger, \& Stein, 1973) and conflict (Gray, 1976), respectively. As well, Schenberg and Graeff (1978) proposed that DPAG-evoked escape responses were inhibited by activation of GABA and 5-HT receptors. The existence of a two-system based behavioral inhibition was further supported by data showing that septal lesion increases responding punished by foot-shock while do not affect responding suppressed by electrical stimulation of DPAG (Graeff \& Rawlins, 1980). In the same vein, Graeff and collaborators showed that 5-HT antagonists failed in releasing the water-reinforced bar-pressing behavior punished by electrical stimulation of DPAG (Morato de Carvalho, de Aguiar, \& Graeff, 1981), thereby discarding the 5-HT pro-aversive effect at DPAG. Finally, Kiser, Brown, Sanghera and German (1980) showed that electrical stimulation of DRN inhibited DPAG-evoked decremental escape. The latter study was further corroborated by behavioral and electrophysiological evidence that the DRN inhibits the DPAG via $5-\mathrm{HT}_{1 \mathrm{~A}}$ receptor neurotransmission (Lovick, 1994; Pobbe \& Zangrossi, 2005; Stezkha \& Lovick, 1994).

Studies carried out with the microinjection of GABAand 5-HT-acting drugs into the DPAG corroborated the data of peripherally injected drugs. Most often, these studies employed the shuttle-box escape paradigm in which the rat has to run to the opposite side of the box to turn off the intracranial stimulus. Data showed that the microinjection of GABA-A and 5-HT antagonists into the DPAG either produced the full-blown defense response or facilitated the escape induced by the stimulation of the same site, respectively. Conversely, the microinjection of drugs which facilitated GABA and 5-HT neurotransmission attenuated DPAG-evoked escape responses (Audi \& Graeff, 1984; Brandão, de Aguiar, \& Graeff, 1982; Graeff, Brandão, Audi, \& Milani, 1986a, Graeff, Brandão, Audi, \& Schutz, 1986b). Finally, Schenberg and collaborators showed that the DPAG-evoked cardiovascular and respiratory responses 
were also attenuated by benzodiazepines injected either peripherally (chlordiazepoxide) or locally (midazolam). Conversely, the latter authors showed that these responses were readily induced by the microinjection of GABA-A antagonists (bicuculine and picrotoxin) into the DPAG (Schenberg, de Aguiar, Salgado, \& Graeff, 1981; Schenberg, de Aguiar, \& Graeff, 1983).

As a result, Graeff (1981) suggested that the antiaversive actions of benzodiazepines and 5-HT agonists were both mediated through the facilitation of GABA neurotransmission within the DPAG. Further studies found that 5-HT antiaversive actions are exerted either directly, through the activation of $5-\mathrm{HT}_{1 \mathrm{~A}}$ inhibitory receptors onto DPAG output neurons, or indirectly, through the activation of $5-\mathrm{HT}_{2 \mathrm{~A}}$ excitatory receptors onto GABA intrinsic neurons of DPAG (Brandão, Lopez-Garcia, Graeff, \& Roberts, 1991; Griffiths \& Lovick, 2002; Pobbe \& Zangrossi, 2005).

These studies supported Graeff's contention that the brain aversive system was the substrate of anxiety (Graeff, 1981, 1987; Graeff et al., 1986a, 1986b). However, in the mid 80's, the growing importance of $\mathrm{PD}$ and the increased dialogue with clinical researchers (Gentil, 1988) had a profound impact on Graeff's ideas. Therefore, following a preliminary report (Graeff, 1988), the DPAG and the raphe-septo-hippocampal system were reinterpreted as the key structures mediating panic and depressive disorders, respectively (Deakin \& Graeff, 1991). In the meanwhile, Jenck, Broekkamp and Van Delft (1990) showed that acute injections of the SSRI panicolytics sertraline and fluvoxamine $(10 \mathrm{mg} / \mathrm{kg})$, but not imipramine and CLM, attenuated the DPAG-evoked shuttle-box escape. Moreover, Jenck, Moreau and Martin (1995) showed that whereas the high-potency panicolytic benzodiazepines alprazolam $(0.3-3.2 \mathrm{mg} /$ $\mathrm{kg})$ and clonazepam $(0.1-1 \mathrm{mg} / \mathrm{kg})$ produced a dosedependent attenuation of DPAG-evoked shuttle-box escape, the putative panicogens yohimbine and CCK, had a facilitatory effect. Accordingly, even though the acute treatments with TCA and SSRIs are ineffective in PD, the inhibitory effects of SSRIs and high-potency benzodiazepines in DPAG-evoked escape were accepted as evidence of the DPAG mediation of panic attacks. These studies were recently extended for several SSRIs, including fluoxetine (FLX, ED $5013.6 \mathrm{mg} / \mathrm{kg}$ ), paroxetine $\left(\mathrm{ED}_{50} 2.9 \mathrm{mg} / \mathrm{kg}\right)$, citalopram $\left(\mathrm{ED}_{50} 6.6 \mathrm{mg} / \mathrm{kg}\right)$ and its active enantiometer, escitalopram $\left(\mathrm{ED}_{50} 3.1 \mathrm{mg} / \mathrm{kg}\right)$ (Hogg, Michan, \& Jessa, 2006).

\section{The role of amygdala in anticipatory anxiety}

To this point, the reader is likely surprised by the omission of the amygdala. Indeed, although Deakin and Graeff (1991) suggested that this structure is crucial in anticipatory anxiety, evidence supporting this proposal stemmed from scientific traditions other than theirs.
The first evidence that the amygdala was involved in innate responses of fear and rage was reported by Klüver and Bucy (1939). These authors showed that monkeys whose temporal lobes were excised became unusually tame to approach. Further experiments showed that definite lesions of the amygdala and hippocampus tamed cats (Ursin, 1965) and monkeys (Smith, 1950; Thompson \& Walker, 1951; Walker, Thompson, \& McQueen, 1953). Conversely, while the electrical stimulation of the amygdala produced predominantly freezing, the responses of fight and flight were also eventually observed (Kaada, Anderson, \& Jansen, 1954; Ursin \& Kaada, 1960).

Around the same time, Hunsperger and collaborators published an influential study showing that electrolytic lesions of PAG blocked the defensive behaviors induced by stimulation of the amygdala and hypothalamus, whereas the inverse did not hold (Fernandez de Molina \& Hunsperger, 1962). Accordingly, these authors suggested a PAG-centered defense system in which the hypothalamus and amygdala played roles only modulatory. This proposal was at variance with old views which regarded the hypothalamus as the central structure of brain defense systems (Hess \& Brugger, 1943). Deakin and Graeff (1991) also adopted a longitudinally organized defense system. However, although they admitted that the DPAG could get visual and auditory information directly from the superior colliculus (SC) (Redgrave \& Dean, 1991), they suggested that the 'anticipatory anxiety' to distal threats, including olfactory cues, was due to the activation of a 'basolateral defense system' comprising the PFC and amygdala. Moreover, they proposed that while the freezing (tense immobility) and directed flight (trotting) to distal threats were mediated by the basolateral defense system and hypothalamus, the explosive flight (galloping, jumping) to a proximal threat was mediated by the DPAG. These assumptions relied mostly on phylogenetic and neuroanatomical considerations, but also on observations that stimulation of the hypothalamus evoked escape responses more directed than those elicited by stimulation of DPAG (Schmitt et al., 1986). In any event, Deakin and Graeff (1991) concluded that fear (and by then, phobias) and situational panic attacks were brought about by a dysfunction of the 'rostral defense system' comprising the medial PFC, amygdala and hypothalamus, whereas spontaneous panic attacks were due the malfunctioning of the 'caudal defense system' of DPAG.

The role of the amygdala in anticipatory anxiety was also supported by the evidence of its participation in aversive learning (Berg \& Davis, 1983; Hitchcock \& Davis, 1986, 1991; Iwata, LeDoux, \& Reis, 1986; LeDoux, Iwata, Cicchetti, \& Reis, 1988; LeDoux, Sakaguchi, \& Reis, 1983; Tishler \& Davis, 1983). These authors showed that nuclei of dorsal amygdala play a crucial role in conditioned fear to a light or tone which was previously paired to a shock. Moreover, they showed that the output of basolateral amygdala (BLA) 
was mediated through distinct pathways from central amygdala (CeA) to the lateral hypothalamus and caudal ventrolateral PAG (VLPAG), in the case of conditioned fear to a tone, or to the ventral cochlear nucleus and nucleus reticularis pontis caudalis, in the case of fearpotentiated startle (Hitchcock \& Davis, 1991; Iwata et al., 1986; LeDoux et al., 1988). Although these data were amply corroborated in the following years, recent studies showed that rhesus monkeys which retained and expressed fear-potentiated startle to a visual cue learned before the complete lesion of the amygdala, failed in acquiring the fear-potentiated startle to an auditory cue when training occurred after the lesion. Thus, the amygdala seems necessary for the acquisition of fearpotentiated startle but not its retention or expression (Antoniadis, Winslow, Davis, \& Amaral, 2007, 2009).

Evidence also suggests that innate and conditioned fears are processed by distinct systems within the amygdala (Walker \& Davis, 1997). Thus, infusions of a glutamate receptor antagonist into the CeA blocked fear-potentiated startle to a conditioned stimulus but not the light-enhanced startle to an unconditioned stimulus. Conversely, infusions into the bed nucleus of the stria terminalis blocked lightenhanced but not fear-potentiated startle. Infusions into the BLA disrupted both phenomena. These findings suggest that the neuroanatomical substrates of fear-potentiated and lightenhanced startle, and perhaps more generally of conditioned and unconditioned fear, may be dissociated. Likewise, Vianna, Graeff, Landeira-Fernandez and Brandão (2001) showed that lesions of the VLPAG which disrupted the conditioned freezing to a context associated with footshocks failed in changing the freezing and escape responses induced by electrical and chemical stimulations of DPAG.

Finally, recent data showed that whereas the lesions of $\mathrm{CeA}$ fail in attenuating the freezing of rats to the odor of the cat (Rosen, 2004), lesions of medial amygdala (MeA) did it effectively (Blanchard, Canteras, Markham, Pentkowski, \& Blanchard, 2005). Based on this and previous studies, Blanchard et al. (2005) proposed that predator odor signals processed within the $\mathrm{MeA}$ are conveyed to the dorsomedial district of ventromedial hypothalamus $(\mathrm{VMH})$ and then to the DPAG-projecting neurons of premammilary dorsal nucleus (PMD) of hypothalamus. Therefore, structures processing the odor of predators are the only system which retained a rostrocaudal organization (vomeronasal organ-amygdalahypothalamus-PAG) akin to that proposed about 50 years ago by Fernandez de Molina and Hunsperger (1962).

Figure 5 illustrates the defense systems involved in innate and proximal threats (upper panel) or in the conditioned fear (bottom panel).

\section{The behavioral inhibition system revisited}

In the early 70 's, the British experimental psychologist Jeffrey A. Gray put forward a neurocognitive model of anxiety that became the most sophisticated interpretation ever made of Papez's and septo-hippocampal classical limbic pathways (Gray 1976, 1982, 1991). Based on Eysenck's (1967) early studies on human personality, Gray proposed that the 'dysthymic personality' of humans and the anxiety-like behaviors of animals were the expression of a 'behavioral inhibition system' (BIS) which core structures were the medial septum and the hippocampus. Gray suggested that BIS functioned as a 'comparator' (Gray, 1991). Thus, if actual stimuli
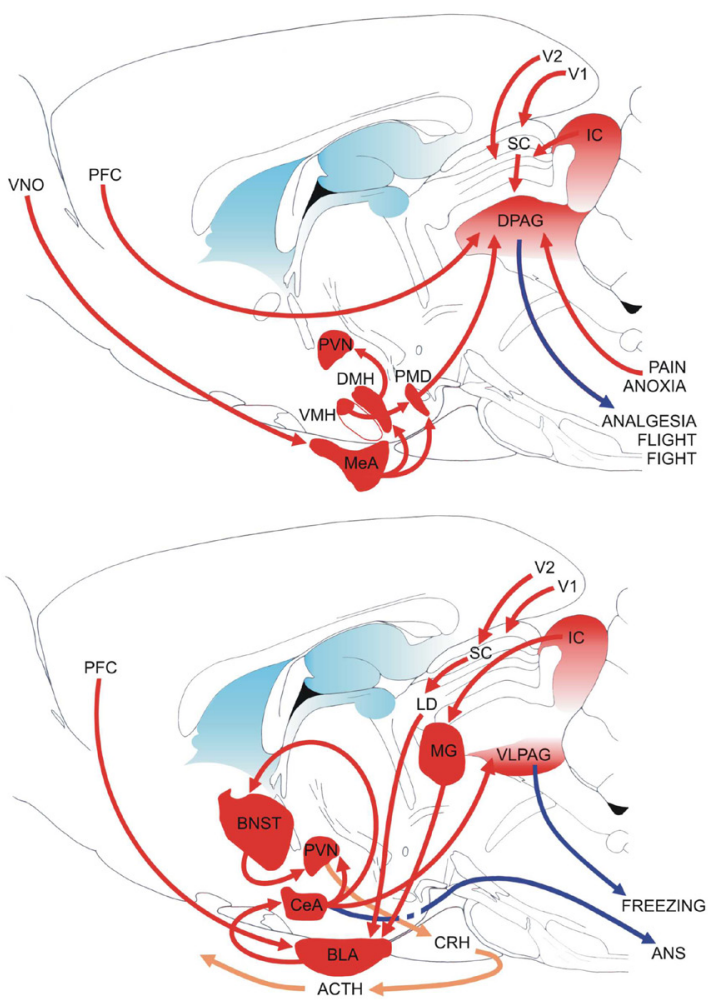

Figure 5. Defensive systems of unconditioned fear responses to proximal threats and interoceptive aversive stimuli (A) and of fear responses to distal threats and conditioned stimuli (B). (A) The dorsal periaqueductal gray matter (DPAG) is a supramedullary reflexive center that receives visual, auditory and somesthesic information from intermediate layers of superior colliculus (SC) which process information from retina, visual cortex (V1,V2), inferior colliculus (IC) and spinal cord. The DPAG also gets olfactory and interoceptive stimuli processed in medial amygdala (MeA), the dorsal 'cap' of ventromedial hypothalamus (VMH) and premmamilary dorsal nucleus of hypothalamus (PMD). DPAG is modulated by pre-frontal cortex (PFC) and produces analgesia and active defensive responses of flight and fight. B) The PFC and basolateral amygdala (BLA) are the key structures of the 'basolateral defense system' processing visual and auditory information from $\mathrm{SC}$ and medial geniculate (MG), and painful stimuli from spinal cord. BLA output is conveyed to $\mathrm{CeA}$ and then to bed nucleus of stria terminalis (BNST), hypothalamus and ventrolateral periaqueductal (VLPAG) areas which mediate the neuroendocrine, autonomic and freezing components of conditioned fear responses Other abbreviations: ACTH - corticotrophin, CORT - corticosterone, $\mathrm{CRH}$ - corticotrophin releasing hormone, $\mathrm{DMH}$ - dorsomedial hypothalamus, PVN - paraventricular nucleus of hypothalamus, (modified from on Deakin and Graeff, 1991). 
match the expectancies of safety and normality, the BIS would operate in the 'checking mode' and behavior control would rest with brain mechanisms involved in foraging, ingestion, reproduction, grooming, sleeping, etc. However, if actual stimuli disagree from expected ones (novelty) or predict punishment, frustration or innate fear, the BIS would operate in 'control mode', inhibiting ongoing behavior via fornix efferents to hypothalamus and increasing arousal and attention. The BIS model was partly based on the disinhibitory effects of lesions of hippocampus and partly on the inhibitory effects of anxiolytic drugs on hippocampal theta rhythm, specially, of the $7.7 \mathrm{~Hz}$ rhythm associated with behavioral inhibition (Gray 1976, 1982, 1991; Gray \& McNaughton, 2000).

Contrarily, however, Deakin and Graeff (1991) suggested that the disinhibition of hippocampuslesioned rats (Jacobs, Trimbach, Eubanks, \& Trulson, 1975) was due to the lack of information about spatial and/or temporal proximity. In this situation freezing was replaced by default primitive reactions of undirected escape leading to the failure of aversive stimuli to inhibit behavior. At that time, this proposal was substantiated by evidence showing that conditioned aversion to context was disrupted by lesions of hippocampus but not of the amygdala (Selden, Everitt, Jarrard, \& Robbins, 1991).

Deakin and Graeff's (1991) relinquishment of Gray's model of BIS was a major rupture in Graeff's early scientific tradition. As a matter of fact, following Blanchard's etho-experimental analysis of antipredator defense levels (Blanchard, Flannelly, \& Blanchard, 1986), Graeff (2004) rescued the BIS as the likely substrate of conflict-like risk-assessment behaviors to a potential threat. In the same vein, Kjelstrup et al. (2002) showed that lesions of the ventral hippocampus (subiculum) increase the exploration of open arms in the elevated plus-maze (EPM), a widespread accepted model of GAD, and reduce the neuroendocrine responses to a brightly lit chamber. Because the rat exploration of EPM implicates the risk assessment of open (dangerous) and closed (safe) arms, these data added new evidence of the role of hippocampus in conflictive behavior. Notably, the selective lesions of dorsal hippocampus and amygdala did not increase the exploration of open arms. Gray's BIS concept was also unexpectedly supported by findings showing that behaviors of male and female rats are predominantly controlled by anxiety and exploratory drives, respectively (Fernandes, Gonzalez, Wilson, \& File, 1999). Indeed, Gray had long shown that the low threshold for the septum elicitation of the 7.7 Hz hippocampal theta rhythm (the 'theta dip') is a testosterone-dependent feature of male rats only (Gray, 1976). Accordingly, because this rhythm was associated with the behavioral inhibition of anxiety, it is tempting to speculate that the increased exploratory drive of female rats is due to the lack of theta dip.
LeDoux and collaborators presented additional evidence of the relative independence of fear-induced behavioral inhibition of Pavlovian conditioned freezing and Estes-Skinner conditioned suppression. Indeed, lesions of VLPAG which blocked the conditioned freezing failed in blocking the suppression of ongoing operant behavior (Amorapanth, Nader, \& LeDoux, 1999). Actually, Gray and McNaughton (2000) argued that conditioned fear to stimuli previously paired to a shock is most probably a model of posttraumatic stress disorder (PTSD). This possibility was supported by recent studies showing that impaired inhibition of conditioned fear (fear-potentiated startle) may be a specific biomarker of PTSD (Jovanovic et al., 2009, 2010a, 2010b).

Finally, Schenberg and collaborators showed that the opposite responses of freezing (tense immobility plus exophthalmus) and flight (trotting, galloping and jumping) could be both produced by small variations in either the intensity or frequency of an electrical stimulus, or dose of an excitatory amino acid applied at a single site of the DPAG (Bittencourt, Carobrez, Zamprogno, Tufik, \& Schenberg, 2004; Schenberg, Costa, Borges, \& Castro, 1990). Further studies showed that DPAGevoked freezing is also distinct from conditioned fear (De Oca, DeCola, Maren, \& Fanselow, 1998; Vianna, Graeff, Landeira-Fernandez, \& Brandão, 2001). Moreover, pharmacological evidence suggests that DPAG-evoked freezing is related to noradrenergic ascending systems involved in attention (Schenberg, Bittencourt, Sudré, \& Vargas, 2001). Therefore, one can safely conclude that there are more systems involved in behavioral inhibition than those conjectured in Gray's BIS and DGH.

\section{The interplay between anxiety and panic}

The DGH states that whereas the 5-HT efferents of DRN facilitate the PFC and amygdala circuits which mediate the avoidance responses during anticipation of threat, they inhibit the circuits of DPAG mediating the fight/flight responses to a proximal threat (Deakin \& Graeff, 1991). Clinical consequences implicate that anxiety inhibits panic. Indeed, these conditions are characterized by passive and active responses, respectively. This possibility is also supported by the precipitation of panic attacks by otherwise misguided techniques of behavioral relaxation (Adler, 1987; Barlow, Craske, Cerny, \& Klosko, 1989). In the same vein, night panic attacks occur during sleep deepening from stage II to III (Hauri, Friedman, \& Ravaris, 1989; Mellman \& Uhde 1989a,b), i.e., just after REM sleep episodes in which the DRN cells are largely silent (Ginty \& Harper, 1976; but see Lu, Jhou, \& Saper, 2006).

Recent evidence from both rats and humans supports the GAD inhibition of PD. In rats, a study from our laboratory showed that whereas the shortterm full-kindling of the amygdala enhances the natural 
flight behaviors against capture, it attenuates the flight behaviors produced by electrical stimulation of DPAG (Tannure, Bittencourt, \& Schenberg, 2009). Therefore, kindling-induced resistance-to-capture is most probably due to a sensitization of circuits other than the DPAG (probably, the 'basolateral defense system'). Yet, because kindling did not affect the performance in the EPM, Tannure et al. (2009) suggested that resistance-tocapture is most probably a model of phobia.

More important, however, Mobbs and colleagues (2001) investigated the spatial imminence of threat by developing an active avoidance paradigm in which volunteers are pursued by a virtual predator endowed with an ability to chase, capture, and inflict real shocks to the finger of the volunteer. Using functional magnetic resonance imaging, they found that as the virtual predator came closer, brain activity shifts from ventromedial PFC/BLA to CeA/PAG. This shift was maximal when a high degree of pain was anticipated. Moreover, PAG activity correlated with the subjective degree of fear and a decreased confidence of escape. Endorsing the DGH, Mobbs et al. (2007) suggested that GAD is mediated by PFC and BLA areas activated by distal threat, whereas panic is mediated by CeA and PAG circuits brought into action by proximal threat. Notably, Amano et al. (1978) have long reported that during a surgery for pain relief, a patient stimulated in the PAG uttered 'somebody is now chasing me, I am trying to escape from him'. While this incidental observation was once regarded as a paranoid delusion of uncertain nature, nowadays it stands out as a sounding proof of the latter study.

\section{Challenging the model}

The contention that DPAG mediates GAD became untenable by the end of the last century. Particularly, in the mid 80's we showed that doses of diazepam as high as $10 \mathrm{mg} / \mathrm{kg}$ (i.p.) failed in attenuating the DPAG-evoked shuttle-box escape (Schenberg, unpublished results). Although these results were accounted to the specific features of shuttle-box in which the rat has to move to the box side in which it was previously punished (Gray, 1976), they also raised the suspicion that the model was not appropriate. On the other hand, the effects of locally injected drugs were difficult to interpret owing to the lack of correlation between intracranial and peripheral doses. For instance, considering that the mean weight of the rat midbrain is about $130 \mathrm{mg}$ and that $98 \%$ of midazolam is bound to plasma proteins, the microinjection of $1 \mathrm{nmol}$ midazolam into the midbrain tectum would correspond to an intravenous dose of $170 \mathrm{mg} / \mathrm{kg}$. Finally, at that time the evidence supporting the DPAG mediation of panic attacks was only based on the acute effects of drugs injected either locally or peripherally (Graeff, 2004). Nevertheless, panicolytic effects of TCAs and SSRIs are known to develop gradually along several weeks.
These problems prompted us to the development of threshold logistic analysis as a convenient way to model the probabilities of intracranially-induced behaviors (Schenberg et al., 1990). Since then, this method has been progressively improved and extensively employed in the mapping of brain defense areas (Bittencourt, Carobrez, Zamprogno, Tufik, \& Schenberg, 2004, Bittencourt, NakamuraPalacios, Mauad, Tufik, \& Schenberg, 2005) and in the assessment of acute and chronic effects of anxiolytics, panicogens and antidepressants on DPAG-evoked defensive behaviors (Schenberg, Bittencourt, Sudré, \& Vargas, 2001; Schenberg, Capucho, Vatanabe, \& Vargas, 2002; Vargas \& Schenberg, 2001).

Briefly, studies with acute injections of antidepressants showed that CLM had variable effects on the thresholds of galloping which were either increased or decreased by the respective doses of 5 and $10 \mathrm{mg} /$ $\mathrm{kg}$. In contrast, the acute injection of FLX produced a moderate but definite increase in the thresholds of immobility $(22 \pm 2 \%)$ and galloping $(25 \pm 3 \%)$ with 1 and $5 \mathrm{mg} / \mathrm{kg}$, respectively. Galloping attenuation by $5 \mathrm{mg} / \mathrm{kg}$ FLX was but paralleled by a facilitation of trotting (Schenberg et al., 2002). Therefore, FLX seems to downgrade the DPAG defensive repertoire towards low-level antipredatory defensive behaviors of freezing and trotting (directed escape). Contrarily, galloping was markedly facilitated by a subconvulsant dose of pentylenetetrazole $(60 \mathrm{mg} / \mathrm{kg}$ ) (Schenberg et al., 2001), a chloride channel blocker which is a putative panicogen in humans (Gentil, 1988). Moreover, drugs lacking panicolytic actions failed in attenuating DPAG-evoked behaviors. Therefore, neither the acute administration of $1.8 \mathrm{mg} / \mathrm{kg}$ diazepam (Schenberg et al., 2001), nor the acute or 10-day administrations of $10 \mathrm{mg} / \mathrm{kg}$ buspirone (Vargas, 2002) produced any increase in the thresholds of DPAG-evoked defensive responses. Accordingly, in spite of the different approaches of intracranial stimulation in the shuttle-box and the open-field, SSRI acute effects were very often converging, supporting the 5-HT inhibition of DPAG-evoked panic-like behaviors.

More important, these studies evaluated the effects of peripheral administrations of CLM and FLX in doses and regimens similar to those employed in the therapy of PD (Schenberg et al., 2001; Vargas \& Schenberg, 2001). Thus, whereas the 21-day administration of saline produced only a moderate but significant increase $(35 \%)$ in the thresholds of galloping, the chronic treatment with CLM produced significant increases in the thresholds of immobility (24\%) and, markedly, of trotting (138\%), galloping (75\%), jumping (45\%) and micturition $(87 \%)$. Although these effects were variable in both timing and response selectivity, they were produced with doses of CLM ( 5 and $10 \mathrm{mg} / \mathrm{kg}$ ) near to those of clinical range (1 to $3 \mathrm{mg} / \mathrm{kg}$ ) (Lotufo-Neto, Bernik, Ramos, Andrade, Gorenstein et al., 2001). Moreover, 
because CLM attenuated both passive (freezing) and active (flight) behaviors, effects were most likely due to an antiaversive action. Although the affinity of CLM for the 5-HT transporter is about 130 times that for the NE transporter, its main metabolite (norclomipramine) is 16 times more selective for the NE transporter. Thus, CLM chronic effects were compared to those of the 21day treatment with FLX doses ( 1 and $5 \mathrm{mg} / \mathrm{kg}$ ) already within the clinical range $(0.2$ to $2 \mathrm{mg} / \mathrm{kg}$ ) (Schneier et al., 1990). Remarkably, the 21-day treatment with $1 \mathrm{mg} /$ $\mathrm{kg}$ FLX produced the selective suppression of galloping without changing the remaining responses (Figure 6).

On the other hand, pre-clinical evidence suggests that anxiety and fear are both related to an increase in the activity of brain noradrenergic neurons. In addition, clinical studies suggest the abnormal regulation of noradrenergic systems in PD (Charney et al., 1990). Nevertheless, electrical stimulation of human locus coeruleus (LC) which caused a 4 to 9 fold increase in NE plasma metabolites produced only alertness (Libet \& Gleason, 1994). Although the latter data makes unlikely the LC contribution to aversiveness, NE may play roles either modulatory or permissive in panic attacks as suggested by several reports of successful treatments of $\mathrm{PD}$ with selective or preferential inhibitors of NE reuptake (Bertani et al., 2004; Dannon, Iancu, \& Grunhaus, 2002; Kalus et al., 1991; Lydiard, 1987, Lydiard et al., 1993; Nardi et al., 2003; Sasson et al., 1999; Seedat et al., 2003; Versiani et al., 2002;). More important, whereas the $\alpha_{2}$-adrenergic antagonist yohimbine is an established panicogen (Bremner,

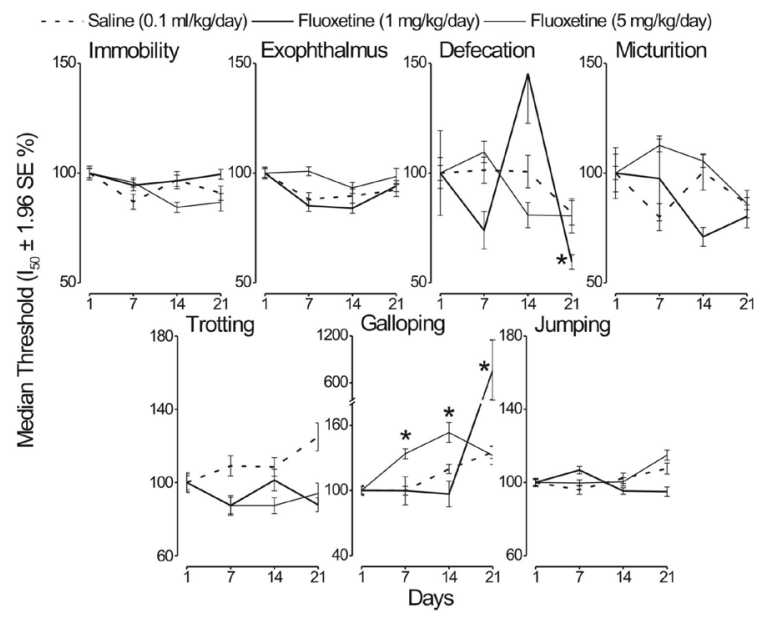

Figure 6. Long-term effects of fluoxetine (1 and $5 \mathrm{mg} / \mathrm{kg} /$ day, i.p.) and saline (.9\% $\mathrm{NaCl}$, i.p.) administered daily for 21 days, on the thresholds of defensive responses induced by electrical stimulation of dorsal periaqueductal gray. Values are the percent variation of median threshold intensities in relation to pre-drug session (day 1). ---- and $* \mathrm{p}<.05$, significantly different from pre-drug controls (regression likelihood ratio coincidence tests and maximum output Pearson's $\chi^{2}$, respectively $)(r=$ responders, $\mathrm{n}=$ number of stimulated rats) (modified from Schenberg, Bittencourt, Sudré, \& Vargas, 2001).
Krystal, Southwick, \& Charney, 1996; Charney, Woods, Goodman, \& Heninger, 1987; Charney, Woods, Krystal, Nagy, \& Heninger, 1992), appropriate doses of the $\alpha_{2}$-adrenergic agonist clonidine promote a rapid but transient improvement of PD patients (Liebowitz, Fyer, McGrath, \& Klein, 1981). Finally, the DPAG sends dense excitatory projections to the LC (Sandkuhler, 1991; Sandkuhler \& Herdegen, 1995).

The DPAG-evoked defensive responses were thus evaluated following the administration of maprotiline (MPT), a NE selective reuptake inhibitor (NSRI) antidepressant that lacks conspicuous panicolytic actions (Westenberg \& Den Boer, 1993). Moreover, these responses were evaluated 6 and 24 hours following the administration of DSP-4, a NE synthesis inhibitor that produces the selective depletion of dorsal noradrenergic bundle (Fritschy \& Grzanna, 1989). To this end, effects were assessed following acute and chronic peripheral treatments with MPT $(10 \mathrm{mg} / \mathrm{kg}$, i.p.), and the acute intracerebroventricular (i.c.v.) injections of MPT $(19.5 \mu \mathrm{g} / 15 \mu \mathrm{L}$, i.c.v. $)$ and DSP-4 $(100 \mu \mathrm{g} / 15 \mu \mathrm{L}$, i.c.v.). Therefore, doses of MPT were about 10 times those employed in the treatment of MD (around $1 \mathrm{mg} / \mathrm{kg}$, p.o.).

Acute injections of MPT inhibited the rat spontaneous behaviors and DPAG-evoked defecation (90\% threshold increase) (Schenberg et al., 2001). In anesthetized rats, Ceci and Borsini (1996) showed that MPT (1-10 $\mathrm{mg} / \mathrm{kg}$, i.v.) excites prefronto-cortical neurons while inhibits the LC. Inhibition of LC is likely due to the activation of autosomic alpha-2 adrenergic receptors (Abercrombie \& Jacobs 1987). The excitation of prefronto cortical neurons is but surprising insofar that the cortical application of NE predominantly inhibits the spontaneous activity while enhances the evoked responses, whereby it increases the signal-to-noise ratio of cerebral cortex (Aston-Jones, Rajkowski, \& Cohen, 2000; Bunney \& Aghajanian 1976; Servan-Schreiber, Printz, \& Cohen, 1990). Accordingly, MPT inhibition of rat spontaneous behaviors was most probably due to the enhancement of cortical activity secondary to the prevalent inhibition of LC.

The MPT attenuation of DPAG-evoked defecation could have been due to effects either central or peripheral at gastrointestinal tract. MPT central effects were but confirmed by the marked increases $(50 \%)$ in the thresholds of defecation following the i.c.v. injections. In turn, acute treatment with MPT produced only light to moderate increases in the thresholds of immobility $(22.5 \%)$, trotting $(23.6 \%)$, exophthalmus $(23.3 \%)$ and galloping (32.5\%) (Lugon, 2006). Although the central dose of MPT (10 $\mu \mathrm{g} / \mathrm{g}$, i.c.v.) was proportionate to that employed in peripheral injections ( $10 \mathrm{mg} / \mathrm{kg}$, i.p.), brain drug levels following i.c.v. injections were most likely higher than those of the latter injections in which the drug is extensively bound to plasma proteins. Likewise, NE depletion with DSP-4 produced significant increases in the thresholds of all defensive responses 6 hours and 
24 hours after the drug injection. Thresholds were but partially recovered 1 week after drug injection (Lugon, 2006). The converging effects of MPT and DSP4 support the inhibition of LC through distinct mechanisms, i.e., stimulation of autosomic $\alpha_{2}$-adrenergic and NE depletion of dorsal noradrenergic bundle.

Notably, the 21-day treatment with MPT caused marked selective increases in the thresholds of immobility $(116 \pm 6 \%$ ) (Figure 7). Therefore, because the LC has a prominent role in visually-guided responses (AstonJones et al., 2000; Delagrange, Canu, Rougeul, Buser, \& Bouyer, 1993), the DPAG-evoked immobility is most likely a NE-mediated attentional shift from nearby targets (e.g., food) to distal ones requiring visual fixation (e.g., predators). The sedative-like effects of the chronic administration of MPT is also supported by previous observations showing that DPAG-evoked immobility is only attenuated by doses already sedative of midazolam $(5.0 \mathrm{mg} / \mathrm{kg})$ (Schenberg et al., 2001). Conversely, the lack of effects of the chronic administration of FLX in DPAGevoked immobility makes it unlikely the relevant role of 5-HT in this response (Vargas \& Schenberg, 2001).

Effects of central injections of MPT and DSP-4 are compatible with the reports of successful treatment of PD with NE reuptake inhibitors both selective and preferential, with the panicolytic action of clonidine and, conversely, the panicogenic properties of yohimbine. Moreover, because DSP-4 promotes the selective depletion of dorsal noradrenergic bundle, the present data suggest that $\mathrm{LC}$ ascending projections are involved with the increased attentiveness of anticipatory anxiety which precedes panic attacks.

The attenuation of DPAG-evoked defensive behaviors following the chronic administration of antidepressants bears a close resemblance with the FLX attenuation of predatorinduced flight behavior in both mice and rats (Blanchard, Griebel, \& Blanchard, 1993; Blanchard, Griebel, Henrie, \& Blanchard, 1997; Griebel et al., 1995; Griebel, Blanchard, \& Blanchard, 1996). It is noteworthy, however, that imipramine $(10 \mathrm{mg} / \mathrm{kg}$, i.p.) was ineffective in these experiments (Vargas, 2002). In any event, the above studies suggest that whereas the DPAG-evoked immobility is a NE-mediated attentional response, galloping is the panic attack best candidate response (Schenberg et al., 2001).

\section{Teasing out panic from stress-related disorders}

The concept of stress was coined by Hans Selye $(1936,1976)$ to denote a complex syndrome produced by a diversity of 'nocuous' agents thereafter known as 'stressors'. Selye's hypothesis had a widespread influence on the medical world, but mostly on immunology and psychiatry. Particularly, clinical and experimental studies implicate stress in MD, PD and PTSD (Jovanovic et al., 2009, 2010a, 2010b; KeenRhinehart et al., 2009; Strohle \& Holsboer, 2003).

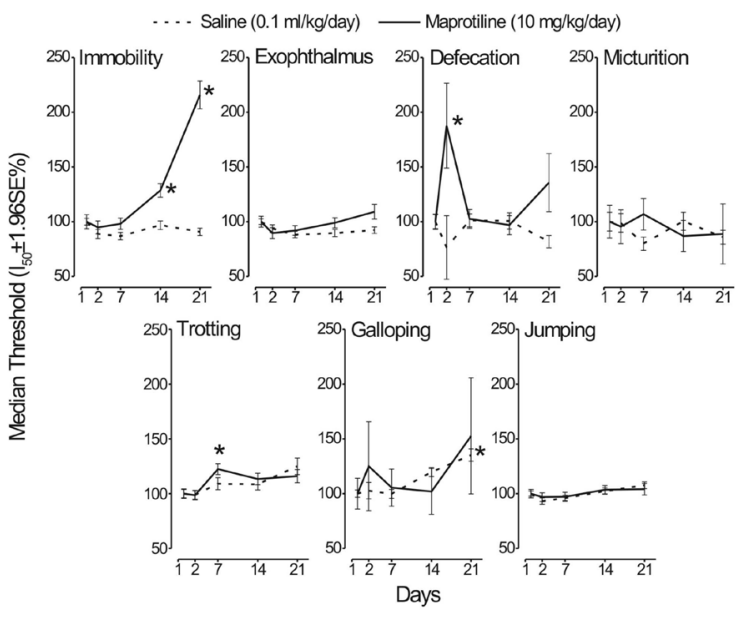

Figure 7.Acute and long-term effects of the 21-day administration of maprotiline $(10 \mathrm{mg} / \mathrm{kg} /$ day, i.p.) or saline $(0.9 \% \mathrm{NaCl}$, i.p. $)$ on the thresholds of defensive responses induced by electrical stimulation of dorsal periaqueductal gray. Values are the percent variation of median threshold intensities in relation to pre-drug session (Day-1). Acute effects were assessed after the daily drug injections (Day-2) and chronic effects before injections (Days 7,14 and 21) so as to separate acute and chronic effects. Other details as in Figure 6 (modified from Schenberg, Bittencourt, Sudré, \& Vargas, 2001).

Selye's hallmark was but the doctrine of the nonspecificity of the 'alarm reaction', i.e., the early activation of the HPA axis that follows the exposure of mammals to a perplexing number of stressors. As a result, there happens a marked increase in plasma levels of corticotrophin (ACTH) and the glucocorticoids cortisol (humans) and corticosterone (rats and other species) (glucocorticoids are both abbreviated as CORT). Further studies showed that prolactin (PRL) is likewise released in response to a great number of stressors both physical and psychological (Dijkstra, Tilders, Hiehle, \& Smelik, 1992; Neill, 1970; Siegel, Conforti, \& Chowers, 1980).

As already mentioned, the demonstration that stress hormones (ACTH, CORT and PRL) remain unaltered during panic attacks is both intriguing and an important clue for the understanding of the neurobiology of PD (Hollander et al., 1989a, 1989b; Kellner, Knaudt, Jahn, Holsboer, \& Wiedemann, 1998; Levin et al., 1987; Liebowitz et al., 1985; Woods et al., 1987, 1988). However, because drugs which induce anxiety ( $\beta$-carboline, yohimbine, metrazol and fenfluramine) and panic (CCK-related peptides) release stress hormones, the unresponsiveness of HPA axis in panic attacks has been hotly debated up to the present days (Graeff et al., 2005; Hollander et al., 1989c). For instance, it has been argued whether the lack of HPA responses is a feature of $\mathrm{CO}_{2}$ - and lactate-induced panics or may be extended to spontaneous panic as well. Yet, in a rare study with spontaneous panic attacks, Cameron, Lee, Curtis and McCann (1987) failed in recording consistent changes in either the CORT or PRL plasma level at the peak or 
10 and 60 minutes after 9 spontaneous panic attacks presented by 4 patients. Likewise, stress hormones did not change following the provocation of situational panic attacks of 15 drug-free agoraphobic patients (Woods et al., 1987). Contrarily, PRL responses tended to be even smaller in patients as compared to controls. Although the latter authors suggested that recurrent panic attacks might have caused an adaptation of the neuroendocrine mechanisms, Anegg et al. (2002) reported that PRL plasma levels did not change, whereas CORT saliva levels in fact decreased in healthy scuba divers who experienced a panic attack during an emergency training in a natural setting. In turn, while the decrease in CORT saliva levels could have been due to mouth rinsing during dive, PRL plasma levels of panic-resistant divers were unexpectedly higher than those of the panicking subjects. This study is particularly important given the straightforward relationship of diving-induced panic attacks and SFA (Klein, 1993; Preter \& Klein, 2008). In addition, a recent study showed that panic patients are remarkably unresponsive to stress despite normal HPA responses to awakening (Petrowski, Herold, Joraschky, Wittchen, \& Kirschbaum, 2010). Finally, stress hormones are not increased in panic-like responses of rats (escape from the open arm of the elevated T-maze, Graeff \& Zangrossi, this issue) and humans (simulated public speaking, Garcia-Leal et al., 2005).

There is some controversy, as well, about the HPA axis responsiveness to $\mathrm{CO}_{2}$. Indeed, whereas the CORT plasma levels of PD patients did not change during or after the panic attacks induced by inhalation of 5 or $7 \%$ $\mathrm{CO}_{2}$ (Sinha et al., 1999; Woods et al., 1988), a single breath of $35 \% \mathrm{CO}_{2}$ produced a significant increase in ACTH, CORT and PRL plasma levels of healthy volunteers (Kaye et al., 2004; van Duinen, Schruers, Maes, \& Griez, 2005). The latter effects were similar in PD patients and controls, and were not correlated with the severity of panic attacks (van Duinen, Schruers, Maes, \& Griez, 2007).

Studies in anesthetized dogs showed that neither the ACTH, nor the CORT are increased following the 20 minute exposure to $6 \% \mathrm{CO}_{2}$. In contrast, the 20 minute exposure to hypoxia produced an increase of $175 \%$ in ACTH plasma level that was attenuated (albeit not abolished) by chronic chemodenervation of carotid body (Raff, Shinsako, \& Dallman, 1984). However, the HPA responses did occur to hypoxia and hypercapnia of higher magnitude (Raff, Shinsako, Keil, \& Dallman, 1983a, 1983b). In conscious rats, the normocapnic hypoxia $\left(7 \% \mathrm{O}_{2}\right)$ caused increases of $100 \%$ in ACTH plasma levels, whereas the acute exposure to $8 \% \mathrm{CO}_{2}$ and the hypercapnic hypoxia produced increases of approximately $200 \%$ and $300 \%$, respectively (Raff \& Roarty, 1988). Responses were but quite different in sustained hypoxia. Thus, the 42 hour exposure to hypoxia (10 and $12.5 \% \mathrm{O}_{2}$ ) failed in changing the levels of both the ACTH and CORT in conscious rats (Raff, Sandri, \& Segerson, 1986). Overall, these studies suggest that the HPA responds differently to low and moderate levels of acute and sustained hypoxia and hypercapnia.

In any event, in a recent review, Graeff et al. (2005) found that neither the real-life panic attacks nor those triggered by physiological panicogens (sodium lactate and $\mathrm{CO}_{2}$ ) are likely to activate the HPA axis. Contrarily, ACTH and CORT are consistently released by panicogens known to produce anticipatory anxiety. Accordingly, anticipatory anxiety and comorbid affective disorders are likely the major confounding factors in clinical studies of HPA responses in human patients (GarciaLeal et al., 2005; Hollander et al., 1989c).

Although the CCK-related peptides (CCK-4, CCK$8 \mathrm{~S}$, pentagastrin) promote panic attacks and activate the HPA axis robustly (Abelson \& Liberzon, 1999; Bradwejn et al., 1992; De Montigny, 1989), these effects might be due to the direct stimulation of the hypothalamus through mechanisms unrelated to panic itself. Thus, in vivo and in vitro studies suggest that $\mathrm{CCK}$ neuroendocrine responses are brought about by the stimulation either direct or indirect (peripherally-mediated) of paraventricular (PVN) and dorsomedial hypothalamus (DMH) (Kamilaris et al., 1992; Kobelt et al., 2006). Also, whereas the chronic treatment with the clinically-effective panicolytic citalopram decreased the intensity of CCK-induced panic attacks, citalopram did not attenuate the HPA axis response to this peptide (Shlik et al., 1997). Finally, CCK-induced panic attacks were shown to be blocked by the $5-\mathrm{HT}_{3}$ antagonist odasentron (Depot et al., 1999), vagotomy (Kamilaris et al., 1992) and CCK-A antagonists (Chen, Deutsch, Gonzalez, \& Gu, 1993; Kamilaris et al., 1992), thereby suggesting the contribution of a peripherally-mediated component.

The demonstration of the lack of HPA axis and PRL responses in an animal model of panic attack is thus an invaluable evidence of a similar mechanism in PD. Therefore, a recent study of our group examined whether the 1-minute stimulation of DPAG of freely-moving rats is accompanied by increases in ACTH and PRL plasma levels. Data showed that neither the freezing reaction, nor the vigorous flight behavior is likely to activate the hypothalamus-pituitary axes (Schenberg, Reis, Póvoa, Tufik, \& Silva, 2008) (Figure 8). Moreover, because panic attacks last 10 minutes or so, we further examined whether the 5-minute stimulation of DPAG (ten 30s on-30s off periods) with the flight threshold intensity activates the HPA axis. Yet, not even the extenuating exertion of repetitive flight bouts produced a significant increase in the ACTH plasma level.

These data are worthy of note for a number of reasons. First, they bring Selye's (1936, 1956, 1976) hypothesis of non-specificity into question. Although criticized since its very beginning, the concept of nonspecificity was tested only recently by Pacak et al. (1998). These authors showed that different stressors 


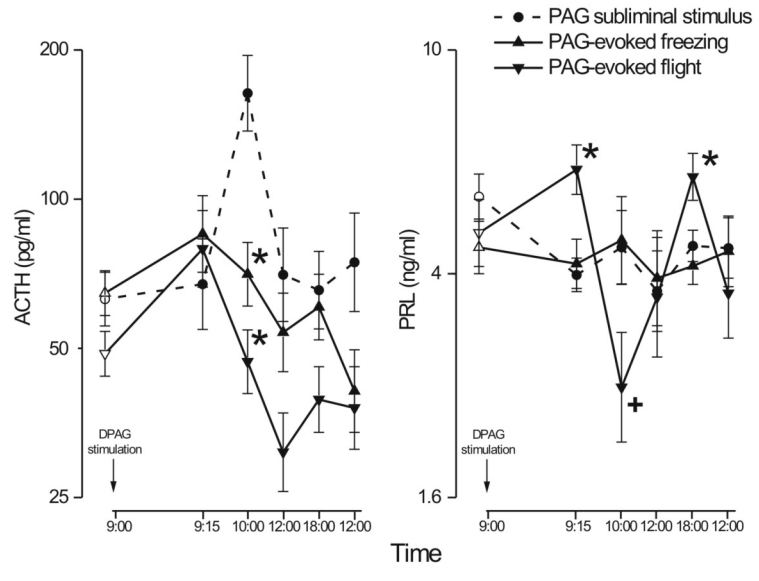

Figure 8. Effects of the 1-min electrical stimulation of dorsal periaqueductal gray matter (DPAG) on corticotropin (ACTH) and prolactin (PRL) plasma levels of Wistar male rats. Hormones were assayed in separate groups. Rats were stimulated with either a subliminal stimulus (ACTH, $n=8$; PRL, $n=11$ ) or the freezing (ACTH, $n=7$; PRL, $n=8)$ and flight (ACTH, $n=7$; PRL, $n=5$ ) threshold intensities. Data represent $\log$-transformed hormone data (mean \pm SEM). Open symbols represent the pre-stimulus baseline levels. Ordinate and abscissa are in logarithmic scales. ${ }^{*} \mathrm{P}<.05$, different from subliminal stimulation (repeated measures ANOVA followed by Bonferroni's t-test of single degree of freedom contrasts for time/group interactions) (Schenberg et al., 2008).

give rise to specific patterns of neuroendocrine responses. Moreover, hormones (ACTH and adrenaline) and transmitters (NE) did not respond proportionally to the same change in the intensity of stress. Therefore, Pacak et al. (1998) suggested that each stress has its 'own signature'. Indeed, Mason (1971) has long shown that whereas the HPA axis was reliably activated by cold and hemorrhage, responses to other stressors were either abolished (fasting, exercise) or reversed (heat) by minimization of psychological stress. Accordingly, Mason (1971) proposed that the apparent non-specificity of HPA axis activation was due to the superimposition of a psychological component (anxiety, suffering) common to most kinds of stressors. Surprisingly, however, we did not observe any significant increase in the stress hormones following the undisputable emotional arousal of the aversive stimulation of DPAG. Second, our findings help in clarifying some clinical studies in which results might have been biased by anticipatory anxiety and comorbid disorders. Lastly, we showed that not even the extreme effort of the prolonged flight behavior activated the HPA axis significantly. Therefore, as far as we know, the lack of HPA axis activation during the intense emotional arousal seems to be a feature unique of DPAG-evoked defense reaction and panic attacks.

Panic attacks are very often misdiagnosed as coronary heart disease (Potokar \& Nutt, 2000), even when symptoms do not involve "fear of dying" (Fleet, Martel, Lavoie, Dupuis, \& Beitman, 2000). Panic patients are also very often referred for pulmonary function testing of chronic obstructive pulmonary disease (Pollack, Kradin, Otto, Worthington, Gould et al., 1996). On the other hand, DPAG stimulation is unquestionably unpleasant in both humans and animals. Thus, there can be little doubt about the subjective experience of panic attack and DPAG stimulation as true emotional stress. Accordingly, HPA and PRL responses are most likely inhibited during panic attacks. Indeed, although the inhibition of the HPA axis during emotional behaviors is rarely observed, the ACTH response to shocks was attenuated when the rat was allowed to fight another rat during the application of the same shock schedule (Conner, Vernikos-Danellis, \& Levine, 1971; Erskine \& Levine, 1973). In the same vein, Bhatnagar et al. (2000) showed that the HPA axis of chronically stressed rats may be inhibited by PAG CCK projections to the posterior paraventricular nucleus of the thalamus. During DPAG-evoked behaviors, the HPA axis could be likewise inhibited by the VLPAG projections to the PVN (Floyd, Keay, Arias, Sawchenko, \& Bandler, 1996). Finally, in the specific case of lactate-induced panic attacks, Kellner et al. (1998) presented evidence that HPA axis could be inhibited by the augmented release of atrium natriuretic hormone, an endogenous antagonist of ACTH.

Whatever the mechanism may be involved, the lack of ACTH and PRL responses following the DPAGevoked defensive behaviors endorse the DPAG-evoked defensive behaviors as a model of panic attack.

\section{Translational modelling of panic attacks}

Besides the pharmacological (Schenberg et al., 2002; Vargas \& Schenberg, 2001) and endocrine (Schenberg et al., 2008) studies above discussed, few research groups carried out animal studies specifically designed to reproduce the unique features of clinical panic.

Among these, Shekhar and collaborators reported a series of experiments that sought to model lactate-induced panic attacks in rats (Johnson \& Shekhar, 2006; Johnson, Truitt, Fitz, Lowry, \& Shekhar, 2008, Johnson et al., 2010; Molosh et al., 2010; Shekhar, 1994; Shekhar, \& Keim, 1997; Shekhar, Keim, Simon, \& McBride, 1996; Shekhar et al., 2006). These studies were based on the previous observation that the inhibition of GABA transmission in the posterior hypothalamus produced increases in locomotor activity 'suggesting an escape reaction' and facilitated the behavioral suppression in experimental conflict and Sidman's nonsignaled avoidance schedule (Shekhar \& DiMicco, 1987; Shekhar, Hingtgen, \& DiMicco, 1987; 1990). Conversely, injections of the GABA-A receptor agonist muscimol in the posterior hypothalamus released punished behavior (Shekhar et al., 1990). Although the involvement of DMH was discarded in the earlier studies, further experiments identified the effective sites in this nucleus properly (Shekhar, Sims, \& Bowsher, 1993). The latter studies also showed 
that blockade or enhancement of GABA-A transmission in the DMH produced increases or decreases in anxiety as measured in the EPM, respectively.

Shekhar's next study was a turning point in these investigations insofar that it showed that DMH-evoked behaviors were blocked by subchronic treatments with the clinically effective panicolytics imipramine ( 5 and $15 \mathrm{mg} / \mathrm{kg}, 7$ days) and clonazepam (5 mg/kg, 3 days). Besides supporting the DMH mediation of panic attacks (Shekhar, 1994), these data were corroborated by studies showing that long-term osmotically-driven infusions of a GABA synthesis inhibitor (allylglycine) in the DMH turned rats sensitive to an intravenous infusion of .5 $\mathrm{M}$ sodium lactate $(10 \mathrm{ml} / \mathrm{kg} / 15 \mathrm{~min})$, as shown by the significant increases in heart rate, blood pressure and anxiety measured through the social interaction (SI) and the EPM tests (Shekhar et al., 2006). Lactate-induced responses were also blocked by glutamate antagonists of ionotropic or metabotropic receptor microinjected into the $\mathrm{DMH}$, and by microinjections of tetrodotoxin in the organum vasculosum lamina terminalis (OVLT) (but not in the subfornical organ) (Shekhar \& Keim, 1997). Furthermore, lactate-induced responses in panicprone rats were facilitated by peripheral injections of yohimbine (Shekhar, Sajdyk, Keim, Yoder, \& Sanders, 1999, Shekhar et al., 2006), but blocked by alprazolam (Shekhar \& Keim, 2000). The involvement of amygdala in lactate-induced autonomic and behavioral effects (SI) were reproduced in rats subjected to chemical kindling of the amygdala through the repeated microinjections into the BLA of antagonists of GABA-A receptor or urocortin, an analogue of corticotrophin releasing hormone (CRH) (Sajdyk, Schober, Gehlert, \& Shekhar, 1999; Sajdyk \& Shekhar, 2000).

However, Shekhar's recent studies raised serious doubts about the homology of lactate-induced panic attacks in rats and humans. First, Johnson and Shekhar (2006) reported that whereas the lactate-evoked responses were facilitated by the microinjection of angiotensin-II in the DMH, they were attenuated by the angiotensin-II antagonists saralasin (non-selective) and losartan (type-1 selective). As a result, these authors concluded that lactate activates angiotensinergic projections from the OVLT to DMH neurons which project in turn to the BNST and CeA to mediate anxietylike behaviors, and to the brainstem sympathetic and parasympathetic nuclei to mediate the cardiovascular and respiratory components of panic responses. Next, Johnson et al. (2010) showed that lactate-induced responses were blocked by antagonists and gene silencing of orexin-1 receptor. Altogether, the latter studies suggest that lactate-induced responses in panicprone rats were mediated by angiotensin and orexin peptides believed to play a crucial role in drinking (Antunes-Rodrigues, Elias, Valença, \& McCann, 2004; Fitzsimons, 2008), feeding (Rodgers, Ishii, Halford, \&
Blundell, 2002) and, in the case of orexin, wakefulness (Siegel, 1999; Taheri, Zeitzer, \& Mignot, 2002). The relationship of lactate-induced responses in rats and drinking mechanisms was further suggested by the puzzling finding of Molosh et al. (2010) showing that panic-like behaviors of panic-prone rats were also produced by the intravenous infusion of $.5 \mathrm{M}$ sodium chloride. Because iso-osmolar infusions of D-mannitol were ineffective, they concluded that panic attacks were the result of the activation of osmosensitive pathways by increased concentrations of sodium, but not lactate. Nevertheless, Kellner et al. (1998) had long shown that neither the PD patients, nor controls presented panic attacks during the intravenous infusion of sodium chloride solutions $(2.7 \%)$ iso-osmolar to $.5 \mathrm{M}$ sodium lactate. Therefore, although we cannot discard the involvement of angiotensin-II and orexin in anxious states accompanying thirst, hunger and eating disorders, the lactate-induced responses in 'panic-prone' rats are unlikely to reproduce the clinical panic. Actually, the behavioral effects of lactate infusions were evaluated in procedures believed to model GAD but not PD.

There are but two more reasons which make unlikely the participation of DMH in panic attacks. First, although the chemical stimulation of $\mathrm{DMH}$ in pentobarbital anesthetized rats produced only small increases in ACTH (70\%) and corticosterone $(80 \%)$ plasma levels, its stimulation in conscious rats increased ACTH plasma levels in about 600\% (Zaretskaia, Zaretsky, Shekhar, \& DiMicco, 2002). Second, recent studies from our laboratory showed that whereas the electrical stimulation of DMH with lowresolution intensity-varying sine-wave pulses elicited all defensive responses of the rat (including the paniclike behaviors of galloping and jumping), stimulation with high-resolution frequency-varying square-wave pulses produced only exophthalmus in the DMH pars diffusa (DMHd) or exophthalmus, immobility, defecation and micturition in the DMH pars compacta (DMHc). The latter responses were also observed following a low-resolution chemical stimulation of DMHd with NMDA. However, in the presence of food, electrical and chemical stimulations of DMHd elicited intensity- and dose-dependent robust ingestive behaviors in sated rats. Conversely, the entire defensive repertoire of the rat, including the panic-like behaviors of galloping and jumping, was produced in three rats which electrodes were inadvertently implanted in the dorsomedial division of VMH (Alves, 2007). These data suggest that the defensive behaviors induced by stimulation of DMHd were most probably due to the current spreading to the latter nucleus. While these data support the involvement of VMH 'cap' in the expression of defensive behaviors (Blanchard et al., 2005), they suggest a limited participation of DMHc if any. As a matter of fact, a recent study reported that the 
electrical stimulation of human VMH produces panic attacks (Wilent et al., 2010).

In turn, Lovick and collaborators carried out several studies showing that the neural excitability of PAG of female rats fluctuates across the estrous cycle (for review see Lovick, 2006, 2008; Lovick \& Devall, 2009). Particularly, neurons of dorsolateral PAG (DLPAG) show a significant increase in the expression of alpha4/beta1/ delta subunits of GABA receptors in the late diestrus as compared to the other phases of the estrous cycle or to their expression in male rats (Lovick, Griffiths, Dunn, $\&$ Martin, 2005). Moreover, these authors showed that most alpha4/beta1/delta GABA receptors of DLPAG are localized in GABA neurons (autoreceptors) as revealed by the double labeling for the corresponding subunits and glutamic acid descarboxilase (Griffits \& Lovick, 2005a, 2005b). Therefore, because the alpha4/beta1/ delta GABA receptors show an outstanding sensitivity to iontophoretic injections of GABA (Lovick et al., 2005), the upregulation of alpha4/beta1/delta autoreceptors is likely to reduce the GABA inhibitory tonus within the DLPAG. Lovick and collaborators suggested that the increased expression of alpha4/beta1/delta autoreceptors may contribute to both the development of LLPDD and to the high comorbidity of LLPDD and PD (Yonkers, Pearlstein, \& Rosenheck, 2003). These mechanisms may also explain the similar susceptibility of PD and LLPDD patients to $\mathrm{CO}_{2}$ (Gorman et al., 2001; Kent et al., 2001) and the higher susceptibility of LLPDD patients to panicogenic challenges in late luteal phase (Le Mellédo, Van, Coupland, Lott, \& Jhangri, 2000). In the same vein, Lovick and collaborators showed that the pressor response, the tachycardia and the tachypnoea produced by systemic injections of a CCK-related panicogen (pentagastrin) were all enhanced in late diestrus. For rats in oestrus, the pressor response and tachycardia but not tachypnoea were also significantly larger than the response evoked in early diestrus (Brack, Jeffery, \& Lovick, 2006). In addition, extracellular recordings from output neurons in the DPAG showed that the increase in firing rate produced by the intravenous administration of pentagastrin or the iontophoretic injection of the GABA-A receptor antagonist bicuculine, is significantly increased during estrus and late diestrus as compared with proestrus and early diestrus (Brack \& Lovick, 2007).

These mechanisms may be complementary to those suggested to underlie LLPDD. Women's bimodal incidence of catamenial epilepsy suggests that brain excitability increases in the middle of the cycle, between the peak of estradiol and the early surge of progesterone, and during the sharp fall of progesterone just before menses (Smith \& Wooley, 2004). However, while the neuroexcitant properties of estradiol are responsible for the increased excitability around the midcycle peak, the higher excitability in early and late luteal phase are most probably associated with changes in the level of the progesterone neuroactive metabolite allopregnanolone $(3 \alpha, 5 \alpha$-THP). However, whereas the acute injections of progesterone and allopregnanolone have conspicuous anxiolytic effects in rats, the 72 hour exposure to progesterone produces increases in anxiety akin those observed in women's early surge of progesterone. Thereafter, anxiety decays to baseline levels despite the sustained exposure of rats to progesterone. Anxiety is but reinstated following the sudden withdrawal of progesterone which mimics the rapid decay of this hormone preceding menses (Gallo \& Smith, 1993; Smith \& Wooley, 2004). Anxiety increases in early and late luteal phases seem to be due to the allopregnanolone upregulation of alpha4 subunit of GABA-insensitive receptors (Gulinello, Gong, Li, \& Smith, 2001, Gulinello, Gong, \& Smith, 2002; Smith, 2002). Indeed, progesterone withdrawal anxiety increases in rats can be prevented by indomethacyn blocking of the breakdown of progesterone to allopregnanolone. Thus, allopregnanolone rather than progesterone is the active compound (Smith et al., 1998). In fact, allopregnanolone levels of LLPDD treated patients were significantly lower in the improved compared with the unimproved subjects. Improvement was also significantly associated with lower allopregnanolone levels for premenstrual depression and appetite changes (Freeman, Frye, Rickels, Martin, \& Smith, 2002). Therefore, the increased incidence of anxiety and panic in late luteal phase seem to be mediated by distinct effects of allopregnanolone in GABA transmission, i.e., the upregulation of alpha4 GABA-insensitive receptors in areas controlling anxiety, or the upregulation of alpha4/beta $/$ delta GABA-sensitive autoreceptors in DPAG, respectively.

A third group of experiments examined the effects of hypothyroidism in DPAG-evoked defensive responses (Siqueira, Rossoni, \& Schenberg, 2010a; Siqueira, Rossoni, Tiengo, Tufik, \& Schenberg, 2010). The relationship between panic attacks and hormone imbalance was originally suggested by Klein (1964) in his pioneering study of the pharmacotherapy of panic and anxiety disorders. Indeed, 12 of 14 patients of the latter study had the first panic attack in a context of endocrine disturbance, including oophorectomy, hysterectomy, post- or pre-partum conditions and unbalanced therapy of hypothyroidism. In order to clarify the conflicting clinical data about the comorbidity of PD and thyroid diseases, recent experiments from our laboratory showed that the systemic injections of low doses of thyrotropin-releasing-hormone (TRH, $1 \mu \mathrm{g}$ / $\mathrm{kg}$, i.p.) produced significant increases in the thresholds of DPAG-evoked responses of immobility (40\%), trotting (33\%), galloping (34\%), jumping (39\%) and exophthalmus (43\%). In contrast, TRH had no effects on EPM arm exploration (Siqueira, Rossoni, \& Schenberg, 2010). In another study, the effects of the anti-thyroid agent methimazole (MTZ) were evaluated either on the panic-like behaviors induced by electrical stimulation of DPAG or the anxiety-like behaviors of rats exposed to 
the EPM. Data showed that the 10-day treatment with MTZ produced marked increases in the thresholds of exophthalmus (65\%), immobility (75\%), trotting (63\%), galloping (56\%), jumping (47\%), defecation (114\%) and micturition (85\%). Effects outlasted the drug discontinuation. In contrast, MTZ had variable effects in the EPM which did not correlate with biochemical indices of hypothyroidism (Siqueira, Rossoni, Tiengo, Tufik, \& Schenberg, 2010b). These studies support the attenuation of panic attacks in hypothyroidism. It remains to be elucidated whether these effects are mediated by DPAG-projecting TRHergic neurons of DRN or by the unique population of TRH neurons in the VLPAG.In any event, the above studies suggest that experiments devised to reproduce the clinical features of PD or the comorbidity of this disorder with other conditions are an obligatory step in the investigation of the neurobiology of PD.

\section{The smothered brain}

Panics induced by lactate, hypercapnia and anoxia were barely discussed in DGH (Deakin \& Graeff, 1991). Conversely, they are the very core of Klein's SFA hypothesis (Klein, 1993; Preter \& Klein, 2008). Although these hypotheses might refer to the otherwise distinct situational and spontaneous panic attacks, the present section examines whether the PAG might harbor a suffocation alarm system.

Breathing is under the control of a widespread network involving structures from caudal medulla up to the hypothalamus, limbic system and cortex. Whereas the latter structures are most probably involved in the thermoregulatory, emotional and volitional respective aspects of respiration, the NTS is the recipient of glossopharyngeal afferents which convey blood gas information from carotid body chemoreceptors (Chitravanashi \& Sapru, 1995; Finley \& Katz, 1992). Among several suprapontine targets (Ricardo \& Koh, 1978), the NTS second order respiratory neurons project to the ventral respiratory nuclei of medulla that control the phrenic nerve activity (Ter Horst \& Streefland, 1994). However, the respiratory drive is likewise dependent on the chemosensitive cholinergic neurons of ventral surface of medulla which senses $\mathrm{pH}$ and $\mathrm{CO}_{2}$ levels of cerebrospinal fluid (Loeschcke, 1958, 1982; Pappenheimer, Fencl, Heisey, \& Held, 1965; Schlaefke, 1981).

In any event, while the peripheral and central chemoreceptors monitor blood/brain gases continuously, panic attacks occur only sporadically, being extremely rare in healthy people. Accordingly, the SFA hypothesis presumes that gas sensors and suffocation alarm systems may operate separately eventually. Uncoupling of these systems would result in panic attacks either spontaneous (upon normal air conditions) or induced by chemicals (lactate, $\mathrm{CO}_{2}, \mathrm{CCK}$, etc). Klein's SFA also predicts that panic attack effectors (i.e., the suffocation alarm system output) are activated by degrees of hypoxia and hypercapnia that produce manifest feelings of breathlessness and 'hunger for air' in either PD patients or healthy volunteers. In mechanically ventilated humans, Banzett, Lansing, Evans and Shea (1996) showed that air hunger threshold is 43 Torr, i.e., only 4 Torr above resting end tidal $\mathrm{PCO}_{2}\left(\mathrm{P}_{\mathrm{ET}} \mathrm{CO}_{2}\right)$. In turn, the 50 Torr $\mathrm{P}_{\mathrm{ET}} \mathrm{CO}_{2}$ produces an unbearable hunger for air. Thresholds and tolerance to $\mathrm{CO}_{2}$ varied among individuals, but did not correlate significantly with the ventilatory response. Hypoxia $\left(\mathrm{P}_{\mathrm{ET}} \mathrm{O}_{2}\right.$ 60-75 Torr) shifted the $\mathrm{P}_{\mathrm{ET}} \mathrm{CO}_{2}$ threshold and tolerance by 2 Torr only and breathing greatly reduced the hunger for air experienced at any $\mathrm{P}_{\mathrm{ET}} \mathrm{CO}_{2}$, increasing the thresholds by 5 Torr and decreasing the sensitivity in about 50\%. More important, while Moosavi et al. (2003) found that hypercapnia and hypoxia have equal potency in producing hunger for air in healthy subjects matched by ventilatory drive, Beck, Shipherd, \& Ohtake (1999) reported that panic patients present increased panic symptoms to both hypercapnia and normocapnic hypoxia. Overall, these data support the presence of a single suffocation alarm system endowed with the capability to integrate the main respiratory inputs $\left(\mathrm{H}^{+} / \mathrm{CO}_{2}, \mathrm{O}_{2}\right)$ and, possibly, lactate brain levels and toxic gases as well. Contrarily, studies carried out in subjects either curarized or quadriplegics suggested that mechanoreceptor afferents play a minor role in producing hunger for air (Banzett, Lansing, Reid, Adams, \& Brown, 1989; Gandevia et al., 1993). Nevertheless, it has been extremely difficult to tease out the suffocation alarm system from respiratory centers controlling eupnoea.

Feelings of breathlessness and hunger for air are most likely processed by supramedullary structures activated during hypoxia and hypercapnia. Cognitive hypotheses suggest that the urge for air arises from 'corollary discharges' of medullary respiratory nuclei conveyed to forebrain structures (Moosavi, Banzett, \& Butler, 2004). This model predicts that the development of hunger for air should parallel the central respiratory responses to both hypoxia and hypercapnia. Because the ventilatory response to sustained hypoxia is a sharp ventilatory increase followed by a slow decay beyond 5 minutes, Moosavi et al. (2004) tested the corollary discharge hypothesis comparing the time course of hunger for air of sustained isocapnic hypoxia in mechanically ventilated healthy subjects to the time course of the ventilatory response of the same subject in separate free-breathing trials. Data showed that during sustained hypoxia of mechanically ventilated healthy subjects, the initial increase in hunger for air is followed by a progressive decline mirroring the biphasic pattern of reflex respiratory response. Admittedly, a mismatch of respiratory drive and forebrain corollary processing could trigger a suffocation false alarm, producing a panic attack. 
Otherwise, the malfunctioning of supramedullary nuclei which take part/modulate the suffocation alarm system could produce panic attacks irrespective of the forebrain processing of respiratory corollary discharges. Indeed, in vivo and in vitro experiments showed that the LC, PAG, raphe nuclei and posterior hypothalamus (PH) have neurons intrinsically sensitive to either hypoxia or hypercapnia (Coates, Li, \& Nattie, 1993; Dillon \& Walldrop, 1992; Kramer, Nolan, \& Waldrop, 1999; Pineda \& Aghajanian, 1997; Ryan \& Waldrop, 1995). Thus, although we cannot discard the abnormal functioning of any respiratory structure, including the peripheral and central chemoreceptors, the unusual sensitivity of $\mathrm{PD}$ patients to $\mathrm{CO}_{2}$ and lactate is most likely due to the dysfunction of supramedullary gas sensors. Be this as it may, it remains to be elucidated why these nuclei become so sensitive in PD patients. Lastly, because gas sensors and suffocation alarm systems are continuously interacting, Klein's hypothesis also predicts that panic attacks could be also susceptible to respiratory maneuvers (exposure to hypercapnia and hypoxia, paced respiration, active hyperventilation, lactate challenge) or respiratoryacting drugs (opioids, progesterone, thyroid hormones, cholinergic agents, etc) (Battaglia, 2002; Klein, 1993; Preter \& Klein, 2008). At any rate, the brain defense structures placed at the crossroad of respiratory pathways from medulla to forebrain are in a strategic position to trigger a panic attack.

\section{Brain areas activated in hypoxia and hypercapnia}

Neuroimaging studies of hypercapnia can provide valuable information about the main structures of the suffocation alarm system. Most often, these studies were performed with the co-registration of magnetic resonance imaging (MRI) and positron emission tomography (PET) scans of suprapontine structures of healthy volunteers which presented definite feelings of smothering, breathlessness or hunger for air during inhalation of $\mathrm{CO}_{2}$ (Brannan et al., 2001; Corfield et al., 1995; Liotti et al., 2001). Particularly, Brannan and colleagues (2001) carried out a detailed study which contrasted the PET scans of hypercapnia $\left(8 \% \mathrm{CO}_{2} / 92 \%\right.$ $\left.\mathrm{O}_{2}\right)$ with those of oxygen inhalation $\left(9 \% \mathrm{~N}_{2} / 91 \% \mathrm{O}_{2}\right)$. Data revealed the activation of a vast array of structures either cortical or subcortical, in one or both sides of the brain. Significant increases in regional cerebral blood flow (rCBF) were found in pons, PAG, midbrain tegmentum, hypothalamus, amygdala and sublenticular periamygdalar region, hippocampus (BA28) and parahippocampal areas (BA 20/36), subgenual anterior cingulated gyrus (BA24), fusiform gyrus (BA19/37), middle temporal gyrus (BA9), anterior insula, pulvinar, putamen/caudatum and several sites in midline and lateral cerebellum. Brain activated areas were also likely to involve the LC, PBA and DRN. In contrast, there were significant deactivations in dorsal anterior cingulated gyrus (ACg, BA24), posterior cingulated cortex (BA23/31) and lateral pre-frontal cortex (BA9/46).

In contrast, structures lighted up during lactate- and CCK-induced panic attacks were only a small subset of the extensive network associated to breathlessness and hunger for air. Most notably, the only structures activated in both the hypercapnia and panic attacks were the subgenual ACg, insula, hypothalamus, PAG, midline cerebellum and, possibly, LC (note that PBA was not activated in either the lactate- or CCK-induced panic attack).

Corroborating the PET pioneering study of lactateinduced panic attacks (Reiman et al., 1989b), exposure to $\mathrm{CO}_{2}$ also activated the temporopolar cortex (Liotti et al., 2001). Because the latter authors employed high-resolution MRI-coupled PET, the activation of temporopolar cortex could not be ascribed to changes in extracerebral blood flow recorded in CCK-induced panics (Benkelfat et al., 1995; Drevets, Videen, MacLeod, Haller \& Raichle, 1992; Javanmard et al., 1999). Thus, the study of Liotti et al. (2001) both rekindles the controversial issue of the activation of temporopolar cortex in lactate-induced panic attacks and suggests that this activation may be due to the lactate conversion to $\mathrm{CO}_{2}$. However, whereas the region of insula/claustrum was only activated in lactateand CCK-induced panic attacks, the temporopolar cortex and parahippocampal gyrus were also activated during anticipatory anxiety of both volunteers and panickers (Reiman, Fusselman, Fox \& Raichle, 1989a).

Because the PET signal is a function of $\mathrm{rCBF}$, the vasodilator properties of $\mathrm{CO}_{2}$ and sodium lactate are a major drawback of above studies (Corfield et al., 1995; Gorman, Kent, Sullivan, \& Coplan, 2000). Actually, the only PET study of a spontaneous panic attack (a singlepatient record) raises a major concern insofar that it reported only deactivations in the right orbitofrontal (BA11), prelimbic (BA25), anterior temporal (BA15) and anterior cingulate (BA32) cortices (Fischer, Andersson, Furmark, \& Fredrikson, 1998).

Otherwise, because c-fos protein expression does not depend on rCBF, c-fos immunohistochemical studies of hypoxia and hypercapnia in animals may be a reliable control of corresponding PET studies in humans. Unfortunately, however, PET human studies were most often focused on suprapontine structures, whereas c-fos animal studies examined pontine and medullary regions (Erickson \& Milhorn, 1994; Haxhiu, Yung, Erokwu, \& Cherniack, 1996; Hirooka, Polson, Potts, \& Dampney, 1997; Sato, Severinghaus, \& Basbaum, 1992; Teppema et al., 1997). Yet, some studies examined c-fos expression up to the rostral midbrain and diencephalon of rats and cats (Berquin, Bodineau, Gros, \& Larnicol, 2000; Larnicol, Wallois, Berquin, Gros, \& Rose, 1994; Teppema et al., 1997). A second difficulty concerns to the rather different protocols of PET and c-fos studies. Thus, whereas the PET human studies employed short exposures (minutes) 
to moderate degrees of hypercapnia (8\%), c-fos animal studies employed long exposures (hours) to varying degrees of hypoxia $(5 \%$ to $11 \%$ ) or to a moderate hypercapnia (15\%) (Berquin et al., 2000; Larnicol et al., 1994; Teppema et al., 1997). Brain activations of rats exposed to hyperoxic hypercapnia $\left(60 \% \quad \mathrm{O}_{2} / 15 \% \quad \mathrm{CO}_{2} / 25 \% \quad \mathrm{~N}_{2}\right)$ were also examined (Teppema et al., 1997).

Exposure to moderate degrees of hypoxia $\left(\begin{array}{ll}8 \% & \mathrm{O}_{2}\end{array}\right)$ produced a significant increase in fos-like immunoreactivity (FLI) in medullary nuclei that play a crucial role in eupnoea (Berquin et al., 2000), including the commissural and caudal NTS and the parapyramidal neurons lying just above the ventral surface of the medulla. Teppema et al. (1997) reported additional labeling in ventrolateral groups of medulla, including the $\mathrm{C} 1$ adrenergic and A1 noradrenergic groups following a similar degree of hypoxia $\left(9 \% \mathrm{O}_{2}\right)$ (labeled cells were found mostly in rostral and caudal ventrolateral nuclei, and none in paragigatocellularis lateralis). The NTS was also activated by $5 \%$ (Berquin et al., 2000) and 15\% $\mathrm{CO}_{2}$ (Teppema et al., 1997). However, the number of labeled cells in rostroventrolateral medulla (RVLM) following the exposure to $15 \% \mathrm{CO}_{2}$ was almost 2.5 times greater than those observed in the $9 \% \mathrm{O}_{2}$ group, corroborating the long known sensitivity of these neurons to hypercapnia (Mitchell \& Hebert, 1974). Interestingly, addition of $60 \% \mathrm{O}_{2}$ to $15 \% \mathrm{CO}_{2}$ greatly reduced the number of $\mathrm{CO}_{2}$ activated cells in both the NTS and RVLM (Teppema et al., 1997). Hypercapnic rats also presented a superficial column of labeled cells in the ventral surface of the medulla $(0-100 \mu \mathrm{m}$ depth) which was absent in hypoxic rats (Teppema et al., 1997). These neurons are part of retrotrapezoid nucleus and may correspond to the paraolivary cell group reported by Berquin et al. (2000).

Neurons of ventral surface of the medulla seem to correspond to the caudal and rostral central sensors of $\mathrm{H}^{+} / \mathrm{CO}_{2}$ formerly suggested by Loeschcke and Koepchen (1958). Indeed, Loeschcke (1982) pointed out that $\mathrm{pH}$ changes of ventral surface of cats produce 'maximal drive of ventilation ... in two areas, one medial to vagal root and the other medial to the hypoglossal root but lateral to the pyramids'. (p.7) Surprisingly, however, pre-Bötzinger/ ventrolateral areas of the medulla which are supposed to play a critical role in eupnoea (Feldman, Mitchell, \& Nattie, 2003) were only activated by the higher level of hypercapnia (15\%) (Teppema et al., 1997).

In dorsolateral pons, the external division of lateral parabrachial area (LPBA) and the Kölliker-Fuse nucleus (KFN) were activated by both the hypercapnia and the hypoxia (Berquin et al., 2000; Teppema et al., 1997). Remarkably, however, midbrain structures not belonging to the established brainstem respiratory nuclei showed significant increases in FLI. Particularly, the DLPAG and VLPAG, as well as the LC and nucleus subcoeruleus, were intensely labeled by moderate degrees of both hypoxia and hypercapnia (yet, despite the high counts of labeled cells in DLPAG of hypoxic rats, values were not statistically significant) (Berquin et al., 2000). Importantly, c-fos labeled neurons of LC of hypercapnic rats were double-stainned for tyrosin hydroxylase (Teppema et al., 1997). These finding agree with in vitro experiments showing that LC neurons are sensitive to $\mathrm{CO}_{2}$ (Pineda \& Aghajanian, 1997). Conversely, the LC was not stained in hypoxic rats (Berquin et al., 2000; Teppema et al., 1997; but see Erickson \& Milhorn, 1994).

More rostrally, Berquin et al. (2000) found significant increases of FLI in $\mathrm{DMH}, \mathrm{PH}$ and in a ventrolateral area extending from the mammillary nuclei to the retrochiasmatic area (ventral hypothalamic zone). Although not significant, there were also FLI increases of $184 \%$ in the PVN of hypoxic rats and of $460 \%$ in the SON (supraoptic nucleus) of hypercapnic rats. Activations of PVN, SON and DMH are likely involved in HPA responses to $\mathrm{CO}_{2}$. Activation of $\mathrm{PH}$ is particularly important insofar that this nucleus harbors hypoxia- and hypercapnia-sensitive neurons that project to the PAG (Ryan \& Waldrop, 1995). In fact, the latter authors suggested that PAG and PBA may be key relays connecting the $\mathrm{PH}$ with medullary nuclei involved in the ventilatory response to both hypoxia and hypercapnia. Lastly, because burrowing species (mole rats) are able to tolerate high levels of hypoxia $\left(7.2 \% \mathrm{O}_{2}\right)$ and hypercapnia (6.1\% $\mathrm{CO}_{2}$ ) (Shams, Avivi, \& Nevo, 2005), it is worth stressing that these conditions lead to similar results in rats and cats (Berquin et al., 2000; Larnicol et al., 1994). Actually, the only difference was the lack of label in the retrotrapezoid nucleus of hypoxic rats.

\section{Evidence of a suffocation alarm system within the periaqueductal gray matter}

During hypercapnia, the only structures activated in both the PET and c-fos studies were the PH, PAG, PBA and, possibly, LC. Except for the PBA, these areas had chemosensitive neurons to $\mathrm{H}^{+} / \mathrm{CO}_{2}$ and/or $\mathrm{O}_{2}$. In contrast, although the cerebellum was examined in both kinds of studies, the regular activation of midline and cortical areas of cerebellum observed during the hypercapnia and experimental panic attacks in humans was not corroborated in c-fos studies of animals exposed to hypercapnia. Indeed, Coates et al. (1993) showed that phrenic nerve activity was markedly increased by microinjections of acetazolamide (an inhibitor of carbonic anhydrase) in several brainstem regions in servo-ventilated paralyzed anesthetized rats and cats which were both vagotomized and glomectomized. Responsive sites at tissue $\mathrm{pH}$ compatible with an endtidal $\mathrm{PCO}_{2}$ of approximately 36 Torr were found within $800 \mu \mathrm{m}$ of the ventrolateral medullary surface, within the vicinity of the NTS and LC. Authors concluded that 
central chemoreceptors are distributed at many locations within the brainstem, all within $1.5 \mathrm{~mm}$ of inner and outer brainstem surface.

The sensitivity PH to both hypoxia and hypercapnia was also supported by whole-cell patch-clamp and extracellular recordings from brain slice preparations (Dillon \& Waldrop, 1992). Extracellular recordings showed that hypoxia stimulated over $80 \%$ of tested neurons in a dose-dependent manner. In addition, more than $80 \%$ of cells excited by hypoxia retained this response during synaptic blockade. In contrast, hypercapnia increased the discharge frequency in only $22 \%$ of neurons. Similarly, whole-cell patch recordings showed that whereas hypoxia produced a depolarization in $76 \%$ of these neurons, depolarization and/or increase in discharge rate were observed in only $35 \%$ of neurons during hypercapnia. These results suggest that separate subpopulations of caudal hypothalamic neurons are sensitive to hypoxia and hypercapnia. Ryan and Waldrop (1995) further demonstrated that PAG-projecting PH neurons were sensitive to both hypoxia $(53 \%)$ and hypercapnia (27\%). Many of these sites were usually referred as belonging to the brain defense system.

More important to the present study, Kramer et al. (1999) showed that the majority (39 of 53) of PAG neurons of rat brain slices responded to hypoxia, $92 \%$ of which with an increase in firing rate. Notably, as well, hypoxia-sensitive neurons in DLPAG/LPAG regions increased firing rates to a greater extent than those located in VLPAG. The former neurons retained the response to hypoxia after tissue perfusion with a low $\mathrm{Ca}^{2+} /$ high $\mathrm{Mg}^{2+}$ solution to block synaptic transmission, thereby supporting their intrinsic sensitivity to a fall of $\mathrm{O}_{2}$ tissue levels. A much smaller proportion (7/33) of neurons responded to hypercapnia.

Although the PAG is not required for respiratory rhythmogenesis, its stimulation is long known for its prominent effects on respiration. Indeed, in the first study ever published with electrical stimulation of PAG, Sachs (1911) reported that among all stimulated regions in the thalamus and midbrain, the PAG yielded the most pronounced respiratory responses, being 'undoubtedly ... a respiratory center'. (p.418) These pioneering observations were corroborated by extensive mapping of electrically-induced respiratory responses (Kabat, 1936). Recent studies showed that chemical stimulation of PAG predominantly affects the respiratory frequency, decreasing the duration of both phases of respiration (Hayward, Swartz, \& Davenport, 2003). Because the chemical stimulation of DPAG produces a marked increase in FLI of LPBA, PAG-evoked respiratory responses are most probably mediated by the latter nucleus (Hayward, Castellanos, \& Davenport, 2004). Moreover, bilateral microinjections of GABA-A agonists or glutamate antagonists in the LPBA produced marked attenuations of DPAG-evoked changes in respiration $(-65 \%$ to $-90 \%)$, heart rate $(-53 \%$ to $-72 \%)$ and, to a lesser degree, blood pressure $(-34 \%$ to $-57 \%)$. These results support a significant role of LPBA in the DPAG-mediated respiratory and cardiac components of defensive behaviors (Hayward et al., 2004; Zhang, Hayward, \& Davenport, 2007).

In spite of the above evidence implicating the $\mathrm{PH}$, PAG, LPBA and LC in the suffocation alarm system, panic patients could present a respiratory dysfunction at any level of respiratory circuits, including central or peripheral chemoreceptors. Indeed, studies in decerebrated cats have long suggested that whereas the baroreceptor activation inhibits the sham-rage behaviors (Bartorelli, Bizzi, Libretti, \& Zanchetti, 1960), chemoreceptor inputs have a facilitatory effect (Bizzi, Libretti, Malliani, \& Zanchetti, 1961). As a matter of fact, incidental observations of Franchini and Krieger (1993) showed that the selective stimulation of carotid chemoreceptors by low doses of potassium cyanide (KCN, $30 \mu \mathrm{g} / \mathrm{kg}$ ) produces defensive behaviors which are reminiscent of those evoked by electrical and chemical stimulations of DLPAG. Recent observations from our laboratory showed that these responses are predominantly alerting, scanning, sniffing, raising and trotting (Schimitel, 2009). However, gallops were also induced at higher doses. The involvement of arterial chemoreceptors in $\mathrm{KCN}$-induced behavioral and respiratory responses was demonstrated by the lack of these responses in rats either sinus-denervated or subjected to the ligation of carotid body artery (Franchini \& Krieger, 1993; Franchini, Oliveira, \& Krieger, 1997). Reciprocally, electrical stimulation of PAG and hypothalamus defense areas was shown to facilitate the chemoreceptor ventilatory response to both KCN and dinitrophenol (Hilton \& Joels, 1965). Finally, Hayward and von Reitzentstein (2002) showed that whereas the chemoreceptor stimulation with $\mathrm{KCN}$ induces c-fos expression throughout the DLPAG and LPAG, baroreceptor stimulation labels only the caudal districts of dorsomedial and lateral columns. This pattern is similar to that induced by systemic hypoxia (Berquin et al., 2000). Hayward and von Reitzentstein (2002) also showed that less than $10 \%$ of neurons of caudal PAG which expressed c-fos after KCN injections were retrogradely labeled from the A5 region of pons which is believed to mediate the pressor component of chemoreceptor reflex (Guyenet \& Koshiya, 1995). Overall, these results support the chemoreceptor facilitation of DPAG-evoked defensive behaviors and, reciprocally, the DPAG facilitation of chemoreceptor ventilatory reflex. More important, however, because Hayward and von Reitzentstein (2002) carried out their experiments in urethane anesthetized rats, $\mathrm{KCN}$ activation of DPAG was not secondary to emotional responses. Rather, they suggest the DPAG intrinsic sensitivity to hypoxic states. 
The DPAG-evoked cardiovascular and respiratory responses have been long associated with the visceral adjustments supportive of fight and flight behaviors (Carobrez, Schenberg, \& Graeff, 1983; Hilton, 1982; Lovick, 1996; Schenberg etal., 1981, 1983; Subramanian, Balnave, \& Holstege, 2008). The detailed study of DPAG-evoked respiratory responses was but carried out only recently by Paydaphar and Eldridge (1987). These authors examined the DPAG-induced facilitation of phrenic nerve activity of sino-aortic denervated vagotomized anesthetized cats kept at constant $\mathrm{P}_{\mathrm{ET}} \mathrm{CO}_{2}$ (30-35 Torr). Data showed that whereas the electrical stimulation of DPAG with supraliminal intensities produces inspiratory apneusis, brief stimulations (1-s trains) with threshold stimuli invariably reset the cycle to inspiratory or expiratory phase. Following cycle resetting, the respiratory rhythm resumed with predictable periodicity. There was but a unique stimulus applied at a definite timing of inspiratory-expiratory transition which resulted in unpredictable time recovery of respiratory cycle (random cophase duration). This response is exactly what would be expected in dyspnoea, the leading symptom of panic attack (Klein, 1993; Preter \& Klein, 2008). Paydaphar and Eldridge (1987) also showed that critically timed stimuli with appropriate intensity resulted in prolonged inspiratory apneusis that lasted up to 3 times the duration of a respiratory cycle. These data show that subtle stimulations of DPAG are able to produce prolonged episodes of dyspnoea which are typical of panic attacks. Altogether, the above data strongly support an anoxia-sensitive suffocation alarm system within the DPAG.

\section{A reconciling hypothesis}

Recently we examined the behavioral effects of $\mathrm{CO}_{2}$-enriched air (0-13\%) or of the cytotoxic anoxia of chemoreceptors by low doses of $\mathrm{KCN}(10-80 \mu \mathrm{g}$, i.v.), administered either alone or combined with electrical stimulation or the electrolytic lesion of DPAG (Schimitel, 2009).

Exposure to $13 \% \mathrm{CO}_{2}$ alone produced a manifest increase in respiration. However, rats either explored the open-field slowly or remained quiet with eyes opened and muscles relaxed as indicated by the lowering of the trunk, head and tail. Similarly, Teppema et al. (1997) had already shown that $\mathrm{CO}_{2}$ concentrations as high as $14 \%$ failed in inducing any defensive behavior in rats. Although hypoactive, rats exposed to low concentrations of $\mathrm{CO}_{2}$ seem not sleepy as indicated by the full opened eyes and the reported activation of LC (Berquin et al., 2000; Teppema et al., 1997).

Exposure to 8 and $13 \% \mathrm{CO}_{2}$ also produced a significant facilitation of defecation and micturition both spontaneous and induced by electrical stimulation of DPAG. Unexpectedly, however, thresholds of DPAG- evoked immobility, trotting and galloping were markedly increased in the presence of $\mathrm{CO}_{2}$. Because the DRN and the VLPAG were shown to be markedly activated by hypercapnia (Berquin et al., 2000; Teppema et al., 1997), the $\mathrm{CO}_{2}$ inhibitory effects of spontaneous behaviors may correspond to the 'hyporeactive immobility' produced by chemical stimulation of VLPAG (Morgan \& Carrive, 2001). For similar reasons, the $\mathrm{CO}_{2}$ attenuation of DPAGevoked defensive responses is most likely due to the activation of VLPAG and DRN inhibitory projections to the DPAG (Brandão, Lopez-Garcia, Graeff, \& Roberts, 1991; Kiser et al., 1980; Lovick, 1992, 1994; Pobbe \& Zangrossi, 2005; Stezkha \& Lovick, 1994).

The respiratory activity was also markedly increased by $\mathrm{KCN}$. However, the $\mathrm{KCN}$ alone produced all defensive responses of the rat in a dose-dependent fashion similar to that produced by stepwise stimulation of DPAG (Bittencourt et al., 2004; Schenberg et al., 2005). Exceptions were jumping, which was elicited in one rat only, and defecation and micturition which effective doses were unusually low as compared to the electrical and chemical effective stimuli. Because the NTS sends profuse efferents to the DPAG (Bandler \& Tork, 1987) and the KCN-induced defensive behaviors are blocked by both the sinus denervation and the ligation of carotid body artery (Franchini \& Krieger, 1993; Franchini et al., 1997), the KCN-evoked defensive behaviors are most probably due to the NTS-mediated chemoreceptor inputs of DLPAG and LPAG (but not VLPAG, see Hayward and von Reizenstein, 2002).

$\mathrm{KCN}$ effects on DPAG-evoked defensive responses were much the opposite of those of hypercapnia. Indeed, $\mathrm{KCN}$ injections facilitated all defensive responses but micturition. Moreover, in spite of the cytotoxic effects of $\mathrm{KCN}$, energy demanding responses of trotting and galloping were more facilitated than the immobility.

Finally, KCN-evoked defensive responses were either blocked (immobility, galloping and jumping) or markedly attenuated (immobility, exophthalmus, defecation and micturition) following the electrolytic lesion of the same sites whose stimulation in screening sessions evoked the defensive responses with intensities below $50 \mu \mathrm{A}$. Although the damage of fibers of passage cannot be discarded, these effects support the existence of an anoxia-sensitive suffocation alarm system within the DPAG.

Evidence suggests that hypoxia and hypercapnia are both sensed through 'tandem acid sensitive potassium channels' (TASK-1 and TASK-3 channels) at carotid body chemoreceptor cells. Indeed, while the TASK inhibitory currents are inhibited by acid $\mathrm{pH}$ and hypoxia, they are activated in alkalosis (Buckler, Williams, \& Honore, 2000; Buckler, 2007; Duprat et al., 1997; Kim, Bang, \& Kim, 2000; Rajan et al., 2000). TASK genes are also expressed in brain chemosensitive areas, including the RVLM, the raphe nuclei and LC (Bayliss, Talley, Sirois, \& Lei, 2001; Talley, Solorzano, Lei, Kim, \& Bayliss, 2001; Washburn, 

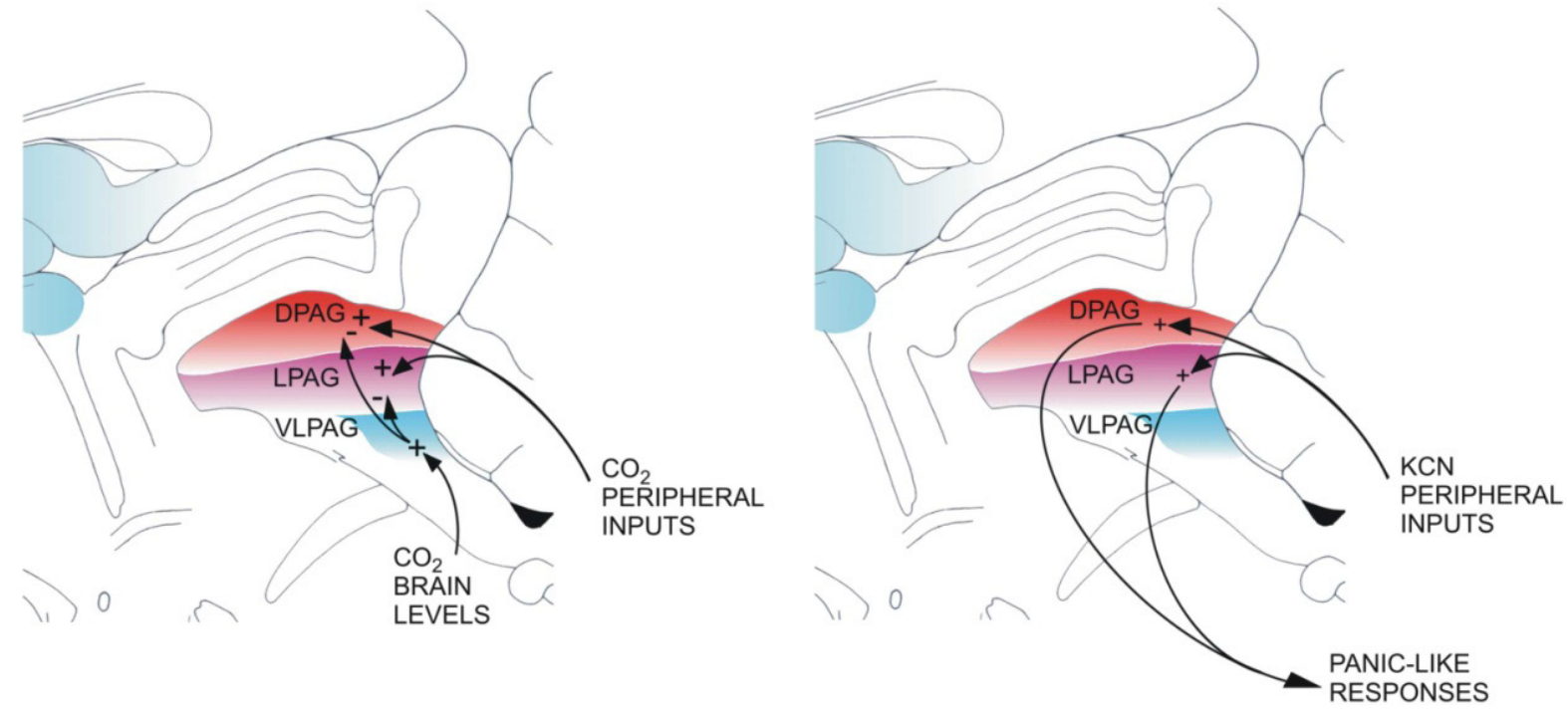

Figure 9. Presumptive mechanisms of sedative- and panic-like responses induced by carbon dioxide $\left(\mathrm{CO}_{2}\right)$ and potassium cyanide (KCN), respectively. Peripheral $\mathrm{CO}_{2}$ inputs to dorsolateral (DLPAG) and lateral (LPAG) periaqueductal gray (PAG) are counteracted by the $\mathrm{CO}_{2}$ direct stimulation of the ventrolateral PAG (VLPAG). In contrast, KCN activates only the DLPAG and LPAG, thereby producing panic-like responses.

Bayliss, \& Guyenet, 2003; Washburn, Sirois, Talley, Guyenet, \& Bayliss, 2002). Therefore, TASK channels may also sense $\mathrm{pH} /$ brain gas levels in areas involved with the detection of both hypoxia and hypercapnia. Yet, evidence above discussed suggests that the suffocation alarm system of the rat triggers distinct behaviors to deal with hypoxia (flight) and hypercapnia (hyporeactive immobility). Thus, it remains to be elucidated why panic patients react to $\mathrm{CO}_{2}$ as it were $\mathrm{KCN}$.

NTS projections to PAG are likely to convey the chemoreceptor information of both hypoxia and hypercapnia. However, while the KCN activated the DLPAG and LPAG (Hayward \& von Reitzenstein, 2002), the hypercapnia activated the LPAG but also the VLPAG and DRN (Berquin et al., 2000). Behavioral and electrophysiological studies suggest that the stimulation of the latter nuclei inhibits the DLPAG and LPAG (Brandão, Lopez-Garcia, Graeff, \& Roberts, 1991; Kiser et al., 1980; Lovick, 1992, 1994; Pobbe \& Zangrossi, 2005; Stezkha \& Lovick, 1994). Therefore, it is tempting to speculate that the $\mathrm{CO}_{2}$ activation of VLPAG and NDR aborted the defensive responses to peripheral signals of hypercapnia. Conversely, hypoxia activates mostly the DLPAG and LPAG, thereby producing the freezing and flight behaviors. Be this as it may, the $\mathrm{CO}_{2}$ hypersensitivity of PD patients could be due to a dysfunction of $\mathrm{CO}_{2}$-sensitive VLPAG/DRN inhibitory projections to the LPAG/DLPAG (Figure 9).

It should be noted, however, that whereas the DLPAG gets extereoceptive stimuli via SC and PMD and projects to nuclei involved in attention (LC) and motor pattern generation (cuneiform nucleus), LPAG and VLPAG project predominantly to the nuclei of the medulla which may mediate the visceral responses that are the hallmark of clinical panic. As a matter of fact, LPAG and VLPAG (but not DLPAG) showed similar activations to the exposure of rats to $5 \% \mathrm{CO}_{2}$ only (Berquin et al., 2000). It is thus suggested that DLPAG and VLPAG outputs are funneled through the LPAG, the very gatekeeper of clinical panic. Conversely, situational panic attacks would activate predominantly the DLPAG, LC and cuneiform nucleus.

The latter proposal is supported by the robust activation of HPA axis following the exposure of preys to predators for periods either short (Figueiredo, Bodie, Tauchi, Dolgas, \& Herman, 2003; Roseboom et al., 2007) or prolonged (Bateson \& Bradshaw, 1997). Therefore, although the predator-induced flight presents a pharmacological profile compatible with panic (Blanchard et al., 1993, 1997; Griebel et al., 1995, 1996), they cannot be equated to clinical panic proper. Most probably, spontaneous panic attacks are, on one hand, due to the activation of LPAG projections to nuclei of the medulla which mediate the visceral responses and, on the other hand, the activation of an 'extra-hypothalamic' loop comprising the DPAG projections to the $\mathrm{LC}$ and thence to the orbitomedial prefrontal cortical areas, of which the ACg projects back to the DPAG (Floyd, Price, Ferry, Keay, \& Bandler, 2000). These circuits are only a subset of a larger circuitry activated during the exposure of preys to predators.

\section{Conclusion}

Even though the animal models are not expected to be the exact reproduction of human psychiatric disorders, the translational modelling of panic attacks is expected to reproduce the main clinical features of $\mathrm{PD}$, including the $\mathrm{CO}_{2}$ and lactate hypersensitivity, the drug treatment 
specificity, the lack of stress hormone responses, the women's higher vulnerability and the high comorbidity of panic with depression and separation anxiety disorders. Thus far, the DPAG model of panic attack fulfilled many requirements, including behavioral, pharmacological, neuroendocrine and sex-dependent features alike those seen in women. The role of DPAG in panic attacks is also supported by complementary data from stimulation and neuroimaging studies in humans. Moreover, KCN experiments support the existence of an anoxiasensitive suffocation alarm system within the DPAG, thereby corroborating the SFA. Nevertheless, $\mathrm{CO}_{2}$ did not facilitate the DPAG-evoked defensive responses. Also, the DPAG-evoked responses were not challenged with lactate. Whether the rat lack of sensitivity to $\mathrm{CO}_{2}$ is a feature of burrowing species or not (Shams, Avivi, \& Nevo, 2005), it remains to be elucidated why panic patients react to $\mathrm{CO}_{2}$ as it were $\mathrm{KCN}$. In any event, the development of animal models of PD allow invasive methods that may reveal brain abnormalities underlying the higher sensitivity of PD patients to both $\mathrm{CO}_{2}$ and lactate. On the other hand, modelling of the comorbidity of PD with separation anxiety and depression implicate the combination of extant experimental models of panic with those of latter disorders. At any rate, there is still a long track ahead before the development of a clinically validated model of panic attacks.

\section{References}

Abelson, J.L.. \& Liberzon, I. (1999). Dose response of adrenocorticotropin and cortisol to the CCK-B agonist pentagastrin. Neuropsychopharmacology, 21, 485-494.

Abercrombie, E.D., \& Jacobs, B.L. (1987). Microinjected clonidine inhibits noradrenergic neurons of the locus coeruleus in freely moving cats. Neuroscience Letters, 76, 203-208

Adler, C.A. (1987). Relaxation-induced panic (RIP); when resting isn't peacefuI. Integrative Psychiatry, 5, 94-112.

Alves, A.C.A. (2007). Behavioral functions of distinct subnuclei of the dorsomedial nucleus of hypothalamus of the rat. Master Degree Thesis: Federal University of Espírito Santo, Vitória, Brazil.

Amano, K., Tanikawa, T., Iseki, H., Kawabatake, H., Notani, M., Kawamura, H., \& Kitamura, K. (1978). Single neuron analysis of the human midbrain tegmentum. Applied Neurophysiology, 41, 66-78.

Amorapanth, P., Nader, K., \& LeDoux, J.E. (1999). Lesions of periaqueductal gray dissociate-conditioned freezing from conditioned suppression behavior in rats. Learning and Memory, 6, 491-499.

Anegg, U., Dietmaier, G., Maier, A., Tomaselli, F., Gabor, S., Kallus, K.W., \& Smolle-Juttner, F.M. (2002). Stress-induced hormonal and mood responses in scuba divers: a field study. Life Sciences, 70, 2721-2734.

Antoniadis, E.A., Winslow, J.T., Davis, M., \& Amaral, D.G. (2007). Role of the primate amygdala in fear-potentiated startle: effects of chronic lesions in the rhesus monkey. Journal of Neuroscience, 27, 7386-7396.

Antoniadis, E.A., Winslow, J.T., Davis, M., \& Amaral, D.G. (2009). The nonhuman primate amygdala is necessary for the acquisition but not the retention of fear-potentiated startle. Biological Psychiatry, 65, 241-248.

Antunes-Rodrigues, J., Castro,M., Elias, L.L., Valenca, M.M., \& McCann, S.M. (2004). Neuroendocrine control of body fluid metabolism. Physiology Reviews, 84, 169-208.

APA (1980). Diagnostic and Statistical Manual of the American Psychiatric Association.American Psychiatric Association:
Washington, DC.

Aston-Jones, G., Rajkowski, J., \& Cohen, J. (2000). Locus coeruleus and regulation of behavioral flexibility and attention. Progress in Brain Research, 126, 165-182.

Audi, E.A., \& Graeff, F.G. (1984). Benzodiazepine receptors in the periaqueductal grey mediate anti-aversive drug action. European Journal of Pharmacology, 103, 279-285.

Bandler, R., \& Tork, I. (1987). Midbrain periaqueductal grey region in the cat has afferent and efferent connection with solitary tract nuclei. Neuroscience Letters, 74, 1-6.

Banzett, R.B., Lansing, R.W., Evans, K.C., \& Shea, S.A. (1996). Stimulus-response characteristics of $\mathrm{CO} 2$-induced air hunger in normal subjects. Respiratory Physiology, 103, 19-31

Banzett, R.B., Lansing, R.W., Reid, M.B., Adams, L., \& Brown, R. (1989). 'Air hunger' arising from increased PCO2 in mechanically ventilated quadriplegics. Respiratory Physiology, 76, 53-67.

Barlow, D.H., Craske, M.G., Cerny, J.A., \& Klosko, J.S. (1989). Behavioral treatment of panic disorder. Behavior Therapy 2, 261-282.

Bartorelli, C., Bizzi, E., Libretti, A., \& Zanchetti, A. (1960). Inhibitory control of sinocarotid pressoceptive afferents on hypothalamic autonomic activity and sham rage behavior. Archives Italienees de Biologie, 98, 308-326.

Bateson, P., \& Bradshaw, E.L. (1997). Physiological effects of hunting red deer (Cervus elaphus). Proceedings of Royal Society of London, B, Biological Sciences, 264, 1707-1714.

Battaglia, M., \& Ogliari, A. (2005). Anxiety and panic: from human studies to animal research and back. Neuroscience and Biobehavioral Reviews, 29, 169-179.

Bayliss, D.A., Talley, E.M., Sirois, J.E., \& Lei, Q. (2001). TASK-1 is a highly modulated $\mathrm{pH}$-sensitive 'leak' $\mathrm{K}(+)$ channel expressed in brainstem respiratory neurons. Respiratory Physiology, 129, 159-174.

Beck, J.G., Ohtake, P.J., \& Shipherd, J.C. (1999). Exaggerated anxiety is not unique to $\mathrm{CO}_{2}$ in panic disorder: a comparison of hypercapnic and hypoxic challenges. Journal of Abnormal Psychology, 108, 473-482.

Benkelfat, C., Bradwejn, J., Meyer, E., Ellenbogen, M., Milot, S., Gjedde, A., \& Evans, A. (1995). Functional neuroanatomy of CCK4-induced anxiety in normal healthy volunteers. American Journal of Psychiatry, 152, 1180-1184.

Berg, W.K., \& Davis, M. (1984). Diazepam blocks fear-enhanced startle elicited electrically from the brainstem. Physiology and Behavior, 32, 333-336.

Bernstein, G.A., Borchardt, C.M., Perwien, A.R., Crosby, R.D., Kushner, M.G., Thuras, P.D., \& Last, C.G. (2000). Imipramine plus cognitive-behavioral therapy in the treatment of school refusal. Journal of American Academy of Childand Adolescent Psychiatry, 39, 276-283.

Berquin, P., Bodineau, L., Gros, F., \& Larnicol, N. (2000). Brainstem and hypothalamic areas involved in respiratory chemoreflexes: a Fos study in adult rats. Brain Research, 857, 30-40.

Bertani, A., Perna, G., Migliarese, G., Di Pasquale, D., Cucchi, M., Caldirola, D., \& Bellodi, L. (2004). Comparison of the treatment with paroxetine and reboxetine in panic disorder: a randomized, single-blind study. Pharmacopsychiatry, 37, 206-210.

Bhatnagar, S., Viau, V., Chu, A., Soriano, L., Meijer, O.C., \& Dallman, M.F. (2000). A cholecystokinin-mediated pathway to the paraventricular thalamus is recruited in chronically stressed rats and regulates hypothalamic-pituitary-adrenal function. Journal of Neuroscience, 20, 5564-5573.

Bittencourt, A.S., Carobrez, A.P., Zamprogno, L.P., Tufik, S., \& Schenberg, L.C. (2004). Organization of single components of defensive behaviors within distinct columns of periaqueductal gray matter of the rat: role of N-methyl-D-aspartic acid glutamate receptors. Neuroscience, 125, 71-89.

Bittencourt, A.S., Nakamura-Palacios, E.M., Mauad, H., Tufik, S., \& Schenberg, L.C. (2005). Organization of electrically and chemically evoked defensive behaviors within the deeper collicular layers as compared to the periaqueductal gray matter of the rat. Neuroscience, 133, 873-892.

Bizzi, E., Libretti, A., Malliani, A., \& Zanchetti, A. (1961). Reflex chemoceptive excitation of diencephalic sham rage behavior. American Journal of Physiology, 200, 923-926.

Blanchard, R., Flannelly, K.J., \& Blanchard, C. (1986). Defensive behavior of laboratory and wild Rattus norvegicus. Journal of Comparative Psychology, 100, 101-107.

Blanchard, D.C., Griebel, G., \& Blanchard, R.J. (2003). The Mouse 
Defense Test Battery: pharmacological and behavioral assays for anxiety and panic. European Journal of Pharmacology, 463, 97-116.

Blanchard, D.C., Canteras, N.S., Markham, C.M., Pentkowski, N.S., \& Blanchard, R.J. (2005). Lesions of structures showing FOS expression to cat presentation: effects on responsivity to a Cat, Cat odor, and nonpredator threat. Neuroscience and Biobehavioral Reviews, 29, 1243-1253.

Blanchard, R., Shepherd, J.K., Rodgers, R.J., Magee, L., \& Blanchard, C. (1993). Attenuation of antipredator defensive behavior in rats following chronic treatment with imipramine. Psychopharmacology (Berl.), 110, 245-253.

Blanchard, R., Griebel, G., Henrie, J.A., \& Blanchard, C. (1997). Differentiation of anxiolytic and panicolytic drugs by effects on rat and mouse defense test batteries. Neuroscience and Biobehavioral Reviews, 21, 783-789.

Brack, K.E., \& Lovick, T.A. (2007). Neuronal excitability in the periaqueductal grey matter during the estrous cycle in female Wistar rats. Neuroscience., 144, 325-335.

Brack, K.E., Jeffery, S.M., \& Lovick, T.A. (2006). Cardiovascular and respiratory responses to a panicogenic agent in anaesthetised female Wistar rats at different stages of the oestrous cycle. European Journal of Neuroscience, 23, 3309-3318.

Bradwejn, J., Koszycki, D., Annable, L., Couetoux, d.T., Reines, S. \& Karkanias, C. (1992). A dose-ranging study of the behavioral and cardiovascular effects of CCK-tetrapeptide in panic disorder. Biological Psychiatry, 32, 903-912.

Brandão, M.L., de Aguiar, J.C., \& Graeff, F.G. (1982). GABA mediation of the anti-aversive action of minor tranquilizers. Pharmacology, Biochemistry and Behavior, 16, 397-402.

Brandão, M.L., Lopez-Garcia, J.A., Graeff, F.G., \& Roberts, M.H. (1991). Electrophysiological evidence for excitatory 5-HT and depressant $5-\mathrm{HT}_{1 \mathrm{~A}}$ receptors on neurones of the rat midbrain tectum. Brain Research, 556, 259-266.

Brannan, S., Liotti, M., Egan, G., Shade, R., Madden, L., Robillard, R., Abplanalp, B., Stofer, K., Denton, D., \& Fox, P.T. (2001). Neuroimaging of cerebral activations and deactivations associated with hypercapnia and hunger for air. Proceedings of the National Academy of Sciences of U.S.A., 98, 2029-2034.

Bremner, J.D., Krystal, J.H., Southwick, S.M., \& Charney, D.S. (1996). Noradrenergic mechanisms in stress and anxiety: II. Clinical studies. Synapse, 23, 39-51.

Buckler, K.J. (2007). TASK-like potassium channels and oxygen sensing in the carotid body. Respiratory Physiology Neurobiology, 157, 55-64.

Buckler, K.J., Williams, B.A., \& Honore, E. (2000). An oxygen-, acid- and anaesthetic-sensitive TASK-like background potassium channel in rat arterial chemoreceptor cells. Journal of Physiology, 525, 135-142.

Bunney, B.S., \& Aghajanian, G.K. (1976). Dopamine and norepinephrine innervated cells in the rat prefrontal cortex: pharmacological differentiation using microiontophoretic techniques. Life Sciences, 19, 1783-1789.

Cameron, O.G., Lee, M.A., Curtis, G.C., \& McCann, D.S. (1987). Endocrine and physiological changes during "spontaneous" panic attacks. Psychoneuroendocrinology, 12, 321-331.

Carobrez, A.P., Schenberg, L.C., \& Graeff, F.G. (1983). Neuroeffector mechanisms of the defense reaction in the rat. Physiology and Behavior, 31, 439-444.

Ceci, A., \& Borsini, F. (1996). Effects of desipramine and maprotiline on the coeruleus-cortical noradrenergic system in anaesthetized rats. European Journal of Pharmacology, 312, 189-193.

Charney, D.S., Woods, S.W., Goodman, W.K., \& Heninger, G.R. (1987). Neurobiological mechanisms of panic anxiety: biochemical and behavioral correlates of yohimbine-induced panic attacks. American Journal of Psychiatry, 144, 1030-1036.

Charney, D.S., Woods, S.W., Krystal, J.H., Nagy, L.M., \& Heninger, G.R. (1992). Noradrenergic neuronal dysregulation in panic disorder: the effects of intravenous yohimbine and clonidine in panic disorder patients. Acta Psychiatrica Scandinavica, 86, 273-282.

Chen, D.Y., Deutsch, J.A., Gonzalez, M.F., \& Gu, Y. (1993). The induction and suppression of c-fos expression in the rat brain by cholecystokinin and its antagonist L364,718. Neuroscience Letters, 149, 91-94.

Clark, D.M., Salkovskis, P.M., Ost, L.G., Breitholtz, E., Koehler, K.A., Westling, B.E., Jeavons, A., \& Gelder, M. (1997). Misinterpretation of body sensations in panic disorder. Journal of Consulting and
Clinical Psychology, 65, 203-213.

Clarke, A., \& File, S.E. (1982). Effects of ACTH, benzodiazepines and 5-HT antagonists on escape from periaqueductal grey stimulation in the rat. Progress in Neuro-Psychopharmacology \& Biological Psychiatry, 6, 27-35.

Coates, E.L., Li, A., \& Nattie, E.E. (1993). Widespread sites of brain stem ventilatory chemoreceptors. Journal of Applied Physiology, 75, 5-14.

Conner, R.L., Vernikos-Danellis, J., \& Levine, S. (1971). Stress, fighting and neuroendocrine function. Nature, 234, 564-566.

Corfield, D.R., Fink, G.R., Ramsay, S.C., Murphy, K., Harty, H.R., Watson, J.D., Adams, L., Frackowiak, R.S., \& Guz, A. (1995). Evidence for limbic system activation during $\mathrm{CO} 2$-stimulated breathing in man. Journal of Physiology, 488, 77-84.

Dannon, P.N., Iancu, I., \& Grunhaus, L. (2002). The efficacy of reboxetine in the treatment-refractory patients with panic disorder: an open label study. Human Psychopharmacology, 17, 329-333.

De Montigny, C. (1989). Cholecystokinin tetrapeptide induces paniclike attacks in healthy volunteers. Preliminary findings. Archives of General Psychiatry, 46, 511-517.

De Oca, B.M., DeCola, J.P., Maren, S., \& Fanselow, M.S. (1998). Distinct regions of the periaqueductal gray are involved in the acquisition and expression of defensive responses. Journal of Neuroscience, 18, 3426-3432.

Deakin, J.F.W., \& Graeff, F.G. (1991). 5 HT and mechanisms of defense. Journal of Psychopharmacology, 5, 305-315.

Delagrange, P., Tadjer, D., Bouyer, J.J., Rougeul, A., \& Conrath, M. (1989). Effect of DSP4, a neurotoxic agent, on attentive behaviour and related electrocortical activity in cat. Behavioral Brain Research, 33, 33-43.

Delgado, J.M.R., Roberts, W.W., \& Miller, N.E. (1954). Learning motivated by electrical stimulation of the brain. American Journal of Physiology, 179, 587-593.

Depot, M., Caille, G., Mukherjee, J., Katzman, M.A., Cadieux, A., \& Bradwejn, J. (1999). Acute and chronic role of 5-HT3 neuronal system on behavioral and neuroendocrine changes induced by intravenous cholecystokinin tetrapeptide administration in humans. Neuropsychopharmacology, 20, 177-187.

Dijkstra, H., Tilders, F.J.H., Hiehle, M.A., \& Smelik, P.G. (1992). Hormonal reactions to fighting in rat colonies prolactin rises during defense, not during offence. Physiology and Behavior, 51, 961-968.

Dillon, G.H., \& Waldrop, T.G. (1992). In vitro responses of caudal hypothalamic neurons to hypoxia and hypercapnia. Neuroscience, $51,941-950$.

Dorow, R., Horowski, R., Paschelke, G., \& Amin, M. (1983). Severe anxiety induced by FG 7142, a beta-carboline ligand for benzodiazepine receptors. Lancet, 2, 98-99.

Drevets, W.C., Videen, T.Q., MacLeod, A.K., Haller, J.W., \& Raichle, M.E. (1992). PET images of blood flow changes during anxiety: correction. Science, 256, 1696.

Duprat, F., Lesage, F., Fink, M., Reyes, R., Heurteaux, C., \& Lazdunski, M. (1997). TASK, a human background $\mathrm{K}+$ channel to sense external $\mathrm{pH}$ variations near physiological $\mathrm{pH}$. EMBO Journal, 16, 5464-5471.

Ehlers, A., Margraf, J., Roth, W.T., Taylor, C.B., Maddock, R.J. Sheikh, J., Kopell, M.L., McClenahan, K.L., Gossard, D., \& Blowers, G.H. (1986). Lactate infusions and panic attacks: do patients and controls respond differently? Psychiatry Research, 17, 295-308.

Erickson, J.T., \& Millhorn, D.E. (1994). Hypoxia and electrical stimulation of the carotid sinus nerve induce Fos-like immunoreactivity within catecholaminergic and serotoninergic neurons of the rat brainstem. Journal of Comparative Neurology, 348, 161-182.

Erskine, M.S., \& Levine, S. (1973). Suppression of pituitary-adrenal activity and shock-induced fighting in rats. Physiology and Behavior, 11, 787-790.

Eysenck, H.J. (1967). The Biological Basis of Personality. Springfield: C. C. Thomas.

Feldman, J.L., Mitchell, G.S., \& Nattie, E.E. (2003). Breathing: rhythmicity, plasticity, chemosensitivity. Annual Review in Neuroscience, 26, 239-266.

Fernandes, C., Gonzalez, M.I., Wilson, C.A., \& File, S.E. (1999). Factor analysis shows that female rat behaviour is characterized primarily by activity, male rats are driven by sex and anxiety. Pharmacology, Biochemistry and Behavior, 64, 731-738.

Fernandez de Molina, A., \& Hunsperger, R.W. (1962). Organization 
of the subcortical system governing defense and flight reactions in the cat. Journal of Physiology, 160, 200-213.

Figueiredo, H.F., Bodie, B.L., Tauchi, M., Dolgas, C.M., \& Herman, J.P. (2003). Stress integration after acute and chronic predator stress: differential activation of central stress circuitry and sensitization of the hypothalamo-pituitary-adrenocortical axis. Endocrinology, 144, 5249-5258.

Finley, J.C., \& Katz, D.M. (1992). The central organization of carotid body afferent projections to the brainstem of the rat. Brain Research, 572, 108-116.

Finley, J.C., \& Katz, D.M. (1992). The central organization of carotid body afferent projections to the brainstem of the rat. Brain Research, 572, 108-116.

Fitzsimons, J.T. (1998). Angiotensin, thirst, and sodium appetite. Physiology Reviews, 78, 583-686.

Fleet, R.P., Martel, J.P., Lavoie, K.L., Dupuis, G., \& Beitman, B.D. (2000). Non-fearful panic disorder: a variant of panic in medical patients? Psychosomatics, 41, 311-320.

Floyd, N.S., Keay, K.A., Arias, C.M., Sawchenko, P.E., \& Bandler, R. (1996). Projections from the ventrolateral periaqueductal gray to endocrine regulatory subdivisions of the paraventricular nucleus of the hypothalamus in the rat. Neuroscience Letters, 220, 105-108.

Floyd, N.S., Price, J.L., Ferry, A.T., Keay, K.A., \& Bandler, R. (2000). Orbitomedial prefrontal cortical projections to distinct longitudinal columns of the periaqueductal gray in the rat. Journal of Comparative Neurology, 422, 556-578.

Franchini, K.G., \& Krieger, E.M. (1993). Cardiovascular responses of conscious rats to carotid body chemoreceptor stimulation by intravenous KCN. Journal of Autonomic Nervous System, 42, 63-69.

Franchini, K.G., Oliveira, V.L., \& Krieger, E.M. (1997). Hemodynamics of chemoreflex activation in unanesthetized rats. Hypertension, 30, 699-703.

Freeman, E.W., Frye, C.A., Rickels, K., Martin, P.A., \& Smith, S.S. (2002). Allopregnanolone levels and symptom improvement in severe premenstrual syndrome. Journal of Clinical Psychopharmacology, 22, 516-520.

Freud, S. (1896). On the right to separate from neurasthenia a definite symptom-complex as "anxiety neurosis". In R. M. Hutchins (Editorin-Chief), Great Books of the Western World, vol. 54, Selected Papers on Hysteria (pp. 25-118). Chicago: The Encyclopaedia Britannica, Inc., 1978.

Fritschy, J.M., \& Grzanna, R. (1989). Immunohistochemical analysis of the neurotoxic effects of DSP-4 identifies two populations of noradrenergic axon terminals. Neuroscience, 30, 181-197.

Gallo, M.A., \& Smith, S.S. (1993). Progesterone withdrawal decreases latency to and increases duration of electrified prod burial: a possible rat model of PMS anxiety. Pharmacology, Biochemistry and Behavior, 46, 897-904.

Gandevia, S.C., Killian, K., McKenzie, D.K., Crawford, M., Allen, G.M., Gorman, R.B., \& Hales, J.P. (1993). Respiratory sensations, cardiovascular control, kinaesthesia and transcranial stimulation during paralysis in humans. Journal of Physiology, 470, 85-107.

Garcia-Leal, C., Parente, A.C., Del-Ben, C.M., Guimaraes, F.S., Moreira, A.C., Elias, L.L., \& Graeff, F.G. (2005). Anxiety and salivary cortisol in symptomatic and nonsymptomatic panic patients and healthy volunteers performing simulated public speaking. Psychiatry Research, 133, 239-252.

Geller, I., \& Blum, K. (1970). The effects of 5-HTP on paraChlorophenylalanine (p-CPA) attenuation of "conflict" behavior. European Journal of Pharmacology, 9, 319-324.

Geller, I., Kulak Jr., J.T., \& Seifter, J. (1962). The effects of chlordiazepoxide and chlorpromazine on a punishment discrimination. Psychopharmacologia, 3, 374-385.

Gentil, V. (1988). The aversive system, 5-HT and panic attacks. In P. Simon, P. Soubrié, \& D. Wildlocher (Eds.), Animal Models of Psychiatric Disorders (pp. 142-145). Basel: Karger.

Gittelman-Klein, R., \& Klein, D.F. (1973). School phobia: diagnostic considerations in the light of imipramine effects. Journal of Mental and Nervous Disease, 156, 199-215.

Goetz, R.R., Gorman, J.M., Dillon, D.J., Papp, L.A., Hollander, E., Fyer, A.J., Liebowitz, M.R., \& Klein, D.F. (1989). Do panic disorder patients indiscriminately endorse somatic complaints? Psychiatry Research, 29, 207-213.

Gorman, J.M., Kent, J., Martinez, J., Browne, S., Coplan, J., \& Papp, L.A. (2001). Physiological changes during carbon dioxide inhalation in patients with panic disorder, major depression, and premenstrual dysphoric disorder: evidence for a central fear mechanism. Archives of General Psychiatry, 58, 125-131.

Gorman, J.M., Kent, J.M., Sullivan, G.M., \& Coplan, J.D. (2000). Neuroanatomical hypothesis of panic disorder, revised. American Journal of Psychiatry, 157, 493-505.

Graeff, F.G. (1981). Minor tranquilizers and brain defense systems. Brazilian Journal of Medical and Biological Research, 14, 239-265.

Graeff, F.G. (1984). The anti-aversive action of minor tranquillizers. Trends in Pharmacological Sciences, 5, 230-233.

Graeff, F.G. (1988). Animal models of aversion. In P. Simon, P. Soubrie, \& D. Wildlocher (Eds.), Selected Models of Anxiety, Depression and Psychosis ( pp. 115-141). Basel: Karger AG.

Graeff, F.G. (2004). Serotonin, the periaqueductal gray and panic. Neuroscience and Biobehavioral Reviews, 28, 239-259.

Graeff, F.G., \& Schoenfeld, R.I. (1970). Tryptaminergic mechanisms in punished and nonpunished behavior. Journal of Pharmacology and Experimental Therapeutics, 173, 277-283.

Graeff, F.G., \& Rawlins, J.N. (1980). Dorsal periaqueductal gray punishment, septal lesions and the mode of action of minor tranquilizers. Pharmacology, Biochemistry and Behavior, 12, 41-45.

Graeff, F.G., \& Silveira Filho, N.G. (1978). Behavioral inhibition induced by electrical stimulation of the median raphe nucleus of the rat. Physiology and Behavior, 21, 477-484.

Graeff, F.G., Brandão, M.L., Audi, E.A., \& Milani, H. (1986). Role of GABA in the anti-aversive action of anxiolytics. Advances in Biochemistry and Psychopharmacology, 42, 79-86

Graeff, F.G., Brandão, M.L., Audi, E.A., \& Schutz, M.T. (1986b). Modulation of the brain aversive system by GABAergic and serotonergic mechanisms. Behavioral Brain Research, 21, 65-72.

Graeff, F.G., Garcia-Leal, C., Del-Ben, C.M., \& Guimaraes, F.S. (2005). Does the panic attack activate the hypothalamic-pituitary-adrenal axis? Anais da Academia Brasileira de Ciências, 77, 477-491

Gray, J.A. (1976). The behavioural inhibition system: a possible substrate for anxiety. In M.P. Feldman, \& A.M. Broadhurst (Eds.), Theoretical and Experimental Bases of Behaviour Modification (pp. 3-41). London: Wiley.

Gray, J.A. (1982). Précis of The Neuropsychology of Anxiety: An Enquiry into the Functions of the Septo-Hippocampal System. Behavioral and Brain Sciences, 5, 469-534.

Gray, J.A. (1991). The Psychology of Fear and Stress. Cambridge: Cambridge University Press.

Gray, J.A., \& McNaughton, N. (2000). The Neuropsychology of Anxiety. Oxford: Oxford Medical Publications.

Griebel, G., Blanchard, C., Jung, A., Lee, J.C., Masuda, C.K., \& Blanchard, R. (1995). Further evidence that the mouse defense test battery is useful for screening anxiolytic and panicolytic drugs: effects of acute and chronic treatment with alprazolam. Neuropharmacology, 34, 1625-1633.

Griebel, G., Blanchard, C., \& Blanchard, R. (1996). Evidence that the behaviors in the Mouse Defense Test Battery relate to different emotional states: a factor analytic study. Physiology and Behavior, $60,1255-1260$.

Griez, E., \& Schruers, K. (1998). Experimental pathophysiology of panic. Journal of Psychosomatic Research, 45, 493-503.

Griffiths, J., \& Lovick, T. (2005). Withdrawal from progesterone increases expression of alpha4, beta 1 , and delta GABA(A) receptor subunits in neurons in the periaqueductal gray matter in female Wistar rats. Journal of Comparative Neurology, 486, 89-97.

Griffiths, J.L., \& Lovick, T.A. (2005). GABAergic neurones in the rat periaqueductal grey matter express alpha4, beta 1 and delta GABAA receptor subunits: plasticity of expression during the estrous cycle. Neuroscience, 136, 457-466.

Gulinello, M., Gong, Q.H., Li, X., \& Smith, S.S. (2001). Short-term exposure to a neuroactive steroid increases alpha4 GABA(A) receptor subunit levels in association with increased anxiety in the female rat. Brain Research, 910, 55-66.

Gulinello, M., Gong, Q.H., \& Smith, S.S. (2002). Progesterone withdrawal increases the alpha4 subunit of the GABA(A) receptor in male rats in association with anxiety and altered pharmacology a comparison with female rats. Neuropharmacology, 43, 701-714.

Guyenet, P.G., \& Koshiya, N. (1995). Working model of the sympathetic chemoreflex in rats. Clinical and Experimental Hypertension, 17, 167-179.

Hartmann, R.J., \& Geller, I. (1971). P-chlorophenylalanine effects on a conditioned emotional response in rats. Life Sciences, 10, 927-933.

Hauri, P.J., Friedman, M., \& Ravaris, C.L. (1989). Sleep in patients 
with spontaneous panic attacks. Sleep, 12, 323-337.

Haxhiu, M.A., Yung, K., Erokwu, B., \& Cherniack, N.S. (1996). CO2induced c-fos expression in the CNS catecholaminergic neurons. Respiratory Physiology, 105, 35-45.

Hayward, L.F., \& Castellanos, M. (2003). Increased c-Fos expression in select lateral parabrachial subnuclei following chemical versus electrical stimulation of the dorsal periaqueductal gray in rats. Brain Research, 974, 153-166.

Hayward, L.F., \& Von Reitzentstein, M. (2002). c-Fos expression in the midbrain periaqueductal gray after chemoreceptor and baroreceptor activation. American Journal of Physiology Heart and Circulatory Physiology, 283, H1975-H1984.

Hayward, L.F., Swartz, C.L., \& Davenport, P.W. (2003). Respiratory response to activation or disinhibition of the dorsal periaqueductal gray in rats. Journal of Applied Physiology, 94, 913-922.

Hayward, L.F., Swartz, C.L., \& Davenport, P.W. (2003). Respiratory response to activation or disinhibition of the dorsal periaqueductal gray in rats. Journal of Applied Physiology, 94, 913-922.

Hayward, L.F., Castellanos, M., \& Davenport, P.W. (2004). Parabrachial neurons mediate dorsal periaqueductal gray evoked respiratory responses in the rat. Journal of Applied Physiology, 96, 1146-1154.

Hess, W.R., \& Brügger, M. (1943). Das subkortikale Zentrum der affectiven Abwerreaktion. Helvetica Physiology and Pharmacology, Acta 1, 33-52.

Hilton, S.M., \& Joels, N. (1965). Facilitation of chemoreceptor reflexes during the defense reaction. Journal of Physiology, 176, 20-22.

Hilton, S.M. (1982). The defense-arousal system and its relevance for circulatory and respiratory control. Journal of Experimental Biology, 100, 159-174.

Hirooka, Y., Polson, J.W., Potts, P.D., \& Dampney, R.A. (1997). Hypoxia-induced Fos expression in neurons projecting to the pressor region in the rostral ventrolateral medulla. Neuroscience, 80, 1209-1224.

Hitchcock, J., \& Davis, M. (1986). Lesions of the amygdala, but not of the cerebellum or red nucleus, block conditioned fear as measured with the potentiated startle paradigm. Behavioral Neuroscience, $100,11-22$

Hitchcock, J.M., \& Davis, M. (1991). Efferent pathway of the amygdala involved in conditioned fear as measured with the fear-potentiated startle paradigm. Behavioral Neuroscience, 105, 826-842.

Hogg, S., Michan, L., \& Jessa, M. (2006). Prediction of anti-panic properties of escitalopram in the dorsal periaqueductal grey model of panic anxiety. Neuropharmacology, 51, 141-145.

Holden, C. (2010). Psychiatry. Experts map the terrain of mood disorders. Science, 327, 1068

Hollander, E., Liebowitz, M.R., Cohen, B., Gorman, J.M., Fyer, A.J., Papp, L.A., \& Klein, D.F. (1989). Prolactin and sodium lactateinduced panic. Psychiatry Research, 28, 181-191.

Hollander, E., Liebowitz, M.R., Gorman, J.M., Cohen, B., Fyer, A., \& Klein, D.F. (1989). Cortisol and sodium lactate-induced panic. Archives of General Psychiatry, 46, 135-140.

Hollander, E., Liebowitz, M.R., DeCaria, C., \& Klein, D.F. (1989). Fenfluramine, cortisol, and anxiety. Psychiatry Research, 31, 211213.

Iwata, J., Ledoux, J.E., \& Reis, D.J. (1986). Destruction of intrinsic neurons in the lateral hypothalamus disrupts the classical conditioning of autonomic but not behavioral emotional responses in the rat. Brain Research, 368, 161-166.

Jacobs, B.L. (1973). Electrophysiological and behavioral effects of electrical stimulation of the raphe nuclei in cats. Physiology and Behavior, 11, 489-495.

Jacobs, B.L., Trimbach, C., Eubanks, E.E., \& Trulson, M. (1975). Hippocampal mediation of raphe lesion and pcpa induced hyperactivity in the rat. Brain Research, 94, 253-261.

Javanmard, M., Shlik, J., Kennedy, S.H., Vaccarino, F.J., Houle, S., \& Bradwejn, J. (1999). Neuroanatomic correlates of CCK-4-induced panic attacks in healthy humans: a comparison of two time points. Biological Psychiatry, 45, 872-882.

Jenck, F., Broekkamp, C.L., \& Van Delft, A.M.L. (1990). The effect of antidepressants on aversive periaqueductal gray stimulation in rats. European Journal of Pharmacology, 177, 201-204.

Jenck, F., Moreau, J.L., \& Martin, J.R. (1995). Dorsal periaqueductal gray-induced aversion as a simulation of panic anxiety: elements of face and predictive validity. Psychiatry Research, 57, 181-191.
Johnson, P.L., \& Shekhar, A. (2006). Panic-prone state induced in rats with GABA dysfunction in the dorsomedial hypothalamus is mediated by NMDA receptors. Journal of Neuroscience, 26, 7093-7104.

Johnson, P.L., Truitt, W.A., Fitz, S.D., Lowry, C.A., \& Shekhar, A. (2008). Neural pathways underlying lactate-induced panic. Neuropsychopharmacology, 33, 2093-2107.

Johnson, P.L., Truitt, W., Fitz, S.D., Minick, P.E., Dietrich, A. Sanghani, S., Traskman-Bendz, L., Goddard, A.W., Brundin, L., \& Shekhar, A. (2010). A key role for orexin in panic anxiety. Nature Medicine, 16, 111-115.

Jovanovic, T., Norrholm, S.D., Fennell, J.E., Keyes, M., Fiallos, A.M., Myers, K.M., Davis, M., \& Duncan, E.J. (2009). Posttraumatic stress disorder may be associated with impaired fear inhibition: relation to symptom severity. Psychiatry Research, 167, 151-160.

Jovanovic, T., Norrholm, S.D., Blanding, N.Q., Phifer, J.E., Weiss, T., Davis, M., Duncan, E., Bradley, B., \& Ressler, K. (2010a). Fear potentiation is associated with hypothalamic-pituitary-adrenal axis function in PTSD. Psychoneuroendocrinology, 35, 846-857.

Jovanovic, T., Norrholm, S.D., Blanding, N.Q., Davis, M., Duncan, E., Bradley, B., \& Ressler, K.J. (2010b). Impaired fear inhibition is a biomarker of PTSD but not depression. Depression and Anxiety, 27, 244-251

Kaada, B.R., Anderson, P., \& Jansen Jr., J. (1954). Stimulation of the amygdaloid nuclear complex in unanesthetized cats. Neurology, 4, 48-64.

Kabat, H. (1936). Electrical stimulation of points in the forebrain and mid brain: the resultant alterations in respiration. Journal of Comparative Neurology, 64, 187-208.

Kalus, O., Asnis, G.M., Rubinson, E., Kahn, R., Friedman, J.M., Iqbal, N., Grosz, D., Van Praag, H.M., \& Cahn, W. (1991). Desipramine treatment in panic disorder. Journal of Affective Disorders, 21, 239-244.

Kamilaris, T.C., Johnson, E.O., Calogero, A.E., Kalogeras, K.T., Bernardini, R., Chrousos, G.P., \& Gold, P.W. (1992). Cholecystokinin-octapeptide stimulates hypothalamic-pituitaryadrenal function in rats: role of corticotropin-releasing hormone. Endocrinology, 130, 1764-1774.

Kaye, J., Buchanan, F., Kendrick, A., Johnson, P., Lowry, C., Bailey, J., Nutt, D., \& Lightman, S. (2004). Acute carbon dioxide exposure in healthy adults: evaluation of a novel means of investigating the stress response. Journal of Neuroendocrinology, 16, 256-264.

Keen-Rhinehart, E., Michopoulos, V., Toufexis, D.J., Martin, E.I., Nair, H., Ressler, K.J., Davis, M., Owens, M.J., Nemeroff, C.B., \& Wilson, M.E. (2009). Continuous expression of corticotropinreleasing factor in the central nucleus of the amygdala emulates the dysregulation of the stress and reproductive axes. MolecularPsychiatry, 14, 37-50.

Kellner, M., Wiedemann, K., \& Holsboer, F. (1992). Atrial natriuretic factor inhibits the CRH-stimulated secretion of ACTH and cortisol in man. Life Sciences, 50, 1835-1842.

Kent, J.M., Papp, L.A., Martinez, J.M., Browne, S.T., Coplan, J.D., Klein, D.F., \& Gorman, J.M. (2001). Specificity of panic response to $\mathrm{CO}_{2}$ inhalation in panic disorder: a comparison with major depression and premenstrual dysphoric disorder. American Journal of Psychiatry, 158, 58-67.

Kim, Y., Bang, H., \& Kim, D. (2000). TASK-3, a new member of the tandem pore $\mathrm{K}(+)$ channel family. Journal of Biological Chemistry, 275, 9340-9347.

Kiser, R.S., \& Lebovitz, R.M. (1975). Monoaminergic mechanisms in aversive brain stimulation. Physiology and Behavior, 15, 47-53.

Kiser, R.S., German, D.C., \& Lebovitz, R.M. (1978). Serotonergic reduction of dorsal central gray area stimulation-produced aversion. Pharmacology, Biochemistry and Behavior, 9, 27-31.

Kiser, R.S., Brown, C.A., Sanghera, M.K., \& German, D.C. (1980). Dorsal raphe nucleus stimulation reduces centrally elicited fearlike behavior. Brain Research, 191, 265-272.

Kjelstrup, K.G., Tuvnes, F.A., Steffenach, H.A., Murison, R., Moser, E.I., \& Moser, M.B. (2002). Reduced fear expression after lesions of the ventral hippocampus. Proceedings of National Academy of Sciences of U.S.A., 99, 10825-10830.

Klein, D.F., \& Fink, M. (1962). Psychiatric reaction patterns to imipramine. American Journal of Psychiatry, 119, 432-438.

Klein, D.F. (1964). Delineation of two drug-responsive anxiety syndromes. Psychopharmacologia, 5, 397-408.

Klein, D.F. (1993). False suffocation alarms, spontaneous panics, and related conditions. An integrative hypothesis. Archives of General 
Psychiatry, 50, 306-317.

Klüver, H., \& Bucy, P.C. (1937). "Psychic blindness" and other symptoms following bilateral temporal lobectomy in rhesus monkeys. American Journal of Physiology, 119, 352-353.

Kobelt, P., Paulitsch, S., Goebel, M., Stengel, A., Schmidtmann, M., van der Voort, I., Tebbe, J.J., Veh, R.W., Klapp, B.F., Wiedenmann, B., Tache, Y., \& Monnikes, H. (2006). Peripheral injection of CCK-8S induces Fos expression in the dorsomedial hypothalamic nucleus in rats. Brain Research, 1117, 109-117.

Kramer, J.M., Nolan, P.C., \& Waldrop, T.G. (1999). In vitro responses of neurons in the periaqueductal gray to hypoxia and hypercapnia. Brain Research, 835, 197-203.

Lapierre, Y.D., Knott, V.J., \& Gray, R. (1984). Psychophysiological correlates of sodium lactate. Psychopharmacology Bulletin, 20, 50-57.

Larnicol, N., Wallois, F., Berquin, P., Gros, F., \& Rose, D. (1994). c-fos-like immunoreactivity in the cat's neuraxis following moderate hypoxia or hypercapnia. Journal de Physiologie (Paris), 88, 81-88.

Le Mellédo, J.M., Van, D.M., Coupland, N.J., Lott, P., \& Jhangri, G.S. (2000). Response to flumazenil in women with premenstrual dysphoric disorder. American Journal of Psychiatry, 157, 821-823.

LeDoux, J.E., Sakaguchi, A., \& Reis, D.J. (1983). Subcortical efferent projections of the medial geniculate nucleus mediate emotional responses conditioned to acoustic stimuli. Journal of Neuroscience, 4, 683-698.

LeDoux, J.E., Iwata, J., Cicchetti, P., \& Reis, D.J. (1988). Different projections of the central amygdaloid nucleus mediate autonomic and behavioral correlates of conditioned fear. Journal of Neuroscience, 8, 2517-2529.

Levin, A.P., Doran, A.R., Liebowitz, M.R., Fyer, A.J., Gorman, J.M., Klein, D.F., \& Paul, S.M. (1987). Pituitary adrenocortical unresponsiveness in lactate-induced panic. Psychiatry Research, $21,23-32$

Libet, B., \& Gleason, C. A. (1994). The human locus coeruleus and anxiogenesis. Brain Research, 634, 178-180.

Liebowitz, M.R., Fyer, A.J., McGrath, P.A., \& Klein, D.F. (1981). Clonidine treatment of panic disorder. Psychopharmacology Bulletin, 17, 122-123.

Liebowitz, M.R., Gorman, J.M., Fyer, A.J., Levitt, M., Dillon, D., Levy, G., Appleby, I.L., Anderson, S., Palij, M., \& Davies, S.O. (1985). Lactate provocation of panic attacks. II. Biochemical and physiological findings. Archives of General Psychiatry, 42, 709-719.

Liebowitz, M.R., Fyer, A.J., Gorman, J.M., Dillon, D., Davies, S., Stein, J.M., Cohen, B.S., \& Klein, D.F. (1985). Specificity of lactate infusions in social phobia versus panic disorders. American Journal of Psychiatry, 142, 947-950.

Liotti, M., Brannan, S., Egan, G., Shade, R., Madden, L., Abplanalp, B., Robillard, R., Lancaster, J., Zamarripa, F.E., Fox, P.T., \& Denton, D. (2001). Brain responses associated with consciousness of breathlessness (air hunger). Proceedings of National Academy of Sciences of U.S.A., 98, 2035-2040.

Loeschcke, H.H. (1982). Central chemosensitivity and the reaction theory. Journal of Physiology, 332, 1-24.

Loeschcke, H.H., Koepchen, H.P., \& Gertz, K.H. (1958). Über den Einflub von Wasserstoffionenkonzentration und $\mathrm{C}_{2}$-Druck im Liquor cerebrospinalis auf die Atmung [Effect of hydrogen ion concentration and carbon dioxide pressure in the cerebrospinal fluid on respiration.]. Pflugers Arch., 266, 569-585.

Lorens, S.A., Sorensen, J.P., \& Yunger, L.M. (1971). Behavioral and neurochemical effects of lesions in the raphe system of the rat Journal of Comparative and Physiological Psychology, 77, 48-52.

Lotufo-Neto, F., Bernik, M., Ramos, R.T., Andrade, L., Gorenstein, C., Cordas, T., Melo, M., \& Gentil, V. (2001). A dose-finding and discontinuation study of clomipramine in panic disorder. Journal of Psychopharmacology, 15, 13-17.

Lovick, T.A. (1992). Inhibitory modulation of the cardiovascular defense response by ventrolateral periaqueductal grey matter in rats. Experimental Brain Research, 89, 133-139.

Lovick, T.A. (1994). Influence of the dorsal and median raphe nuclei on neurons in the periaqueductal gray matter: role of 5-hydroxytryptamine. Neuroscience, 59, 993-1000.

Lovick, T.A. (1996). Midbrain and medullary regulation of defensive cardiovascular functions. Progress in Brain Research, 107, 301-313.

Lovick, T.A. (2006). Plasticity of GABA(A) receptor subunit expression during the oestrous cycle of the rat: implications for premenstrual syndrome in women. Experimental Physiology, 91,
655-660.

Lovick, T.A. (2008). GABA in the female brain - oestrous cyclerelated changes in GABAergic function in the periaqueductal grey matter. Pharmacology Biochemistry and Behavior, 90, 43-50.

Lovick, T.A., Griffiths, J.L., Dunn, S.M., \& Martin, I.L. (2005). Changes in GABA(A) receptor subunit expression in the midbrain during the oestrous cycle in Wistar rats. Neuroscience, 131, 397-405.

Lovick, T.A., \& Devall, A.J. (2009). Progesterone withdrawal-evoked plasticity of neural function in the female periaqueductal grey matter. Neural Plasticity, 2009, 730902.

Lu, J., Jhou, T.C., \& Saper, C.B. (2006). Identification of wake-active dopaminergic neurons in the ventral periaqueductal gray matter. Journal of Neuroscience, 26, 193-202.

Lugon, A.B. (2006). Role of Central Noradrenergic System in the Defensive Behaviors produced by Electrical Stimulation of Periaqueductal Gray Matter of Rats. Master Degree Thesis: Federal University of Espírito Santo, Vitória, Brazil.

Lydiard, R.B. (1987). Successful utilization of maprotiline in a panic disorder patient intolerant of tricyclics. Journal of Clinical Psychopharmacology, 7, 113-114.

Lydiard, R.B., Morton, W.A., Emmanuel, N.P., Zealberg, J.J., Laraia, M.T., Stuart, G.W., O’Neil, P.M., \& Ballenger, J.C. (1993). Preliminary report: placebo-controlled, double-blind study of the clinical and metabolic effects of desipramine in panic disorder. Psychopharmacology Bulletin, 29, 183-188.

Margraf, J., Ehlers, A., \& Roth, W.T. (1986). Sodium lactate infusions and panic attacks: a review and critique. Psychosomomatic Medicine, 48, 23-51.

Margules, D.L., \& Stein, L. (1969a). Cholinergic synapses in the ventromedial hypothalamus for the suppression of operant behavior by punishment and satiety. Journal of Physiological Psychology, 67, 327-335

Margules, D.L., \& Stein, L. (1969b). Cholinergic synapses of a periventricular punishment system in the medial hypothalamus. American Journal of Physiology, 217, 475-480.

Mason, J.W. (1971). A re-evaluation of the concept of "non-specificity" in stress theory. Journal of Psychiatric Research, 8, 323-333.

McNaughton, N., \& Corr, P.J. (2004). A two-dimensional neuropsychology of defense: fear/anxiety and defensive distance. Neuroscience and Biobehavioral Reviews, 28, 285-305.

Mellman, T.A., \& Uhde, T.W. (1989a). Electroencephalographic sleep in panic disorder. A focus on sleep-related panic attacks. Archives of General Psychiatry, 46, 178-184.

Mellman, T.A., \& Uhde, T.W. (1989b). Sleep panic attacks: new clinical findings and theoretical implications. American Journal of Psychiatry, 146(9), 1204-1207.

Mitchell, R.A., \& Herbert, D.A. (1974). The effect of carbon dioxide on the membrane potential of medullary respiratory neurons. Brain Research, 75, 345-349.

Mobbs, D., Petrovic, P., Marchant, J.L., Hassabis, D., Weiskopf, N., Seymour, B., Dolan, R.J., \& Frith, C.D. (2007). When fear is near: threat imminence elicits prefrontal-periaqueductal gray shifts in humans. Science, 317, 1079-1083.

Molosh, A.I., Johnson, P.L., Fitz, S.D., DiMicco, J.A., Herman, J.P., \& Shekhar, A. (2010). Changes in central sodium and not osmolarity or lactate induce panic-like responses in a model of panic disorder. Neuropsychopharmacology, 35, 1333-1347.

Moosavi, S.H., Golestanian, E., Binks, A.P., Lansing, R.W., Brown, R., \& Banzett, R.B. (2003). Hypoxic and hypercapnic drives to breathe generate equivalent levels of air hunger in humans. Journal of Applied Physiology, 94, 141-154.

Moosavi, S.H., Banzett, R.B., \& Butler, J.P. (2004). Time course of air hunger mirrors the biphasic ventilatory response to hypoxia. Journal of Applied Physiology, 97, 2098-2103.

Morato de Carvalho, S., de Aguiar, J.C., \& Graeff, F.G. (1981). Effect of minor tranquilizers, tryptamine antagonists and amphetamine on behavior punished by brain stimulation. Pharmacology, Biochememistry and Behavior, 15, 351-356.

Morgan, M.M., \& Carrive, P. (2001). Activation of the ventrolateral periaqueductal gray reduces locomotion but not mean arterial pressure in awake, freely moving rats. Neuroscience, 102, 905-910.

Nardi, A.E., Nascimento, I., Valenca, A.M., Lopes, F.L., Mezzasalma, M.A., Zin, W.A., \& Versiani, M. (2003). Respiratory panic disorder subtype: acute and long-term response to nortriptyline, a noradrenergic tricyclic antidepressant. Psychiatry Research, 120, 283-293 
Nashold Jr., B.S., Wilson, W.P., \& Slaughter, D.G. (1969). Sensations evoked by stimulation in the midbrain of man. Journal of Neurosurgery, 30, 14-24

Neill, J.D. (1970). Effects of "stress" on serum prolactin and luteinizing hormone levels during the estrous cycle of the rat. Endocrinology, 87, 1192-1197.

Olds, J., \& Milner, P. (1954). Positive reinforcement produced by electrical stimulation of septal area and other regions of rat brain. Journal of Comparative and Physiological Psychology, 47, 419-427.

Olds, M.E., \& Olds, J. (1963). Approach-avoidance analysis of rat diencephalon. Journal of Comparative Neurology, 120, 259-295.

Pacak, K., Palkovits, M., Yadid, G., Kvetnansky, R., Kopin, I.J., \& Goldstein, D.S. (1998). Heterogeneous neurochemical responses to different stressors: a test of Selye's doctrine of nonspecificity. American Journal of Physiology, 275, R1247-R1255.

Pappenheimer, J.R., Fencl, V., Heisey, S.R., \& Held, D. (1965). Role of cerebral fluids in control of respiration as studied in unanesthetized goats. American Journal of Physiology, 208, 436-450.

Paydarfar, D., Eldridge, F.L., \& Kiley, J.P. (1986). Resetting of mammalian respiratory rhythm: existence of a phase singularity. American Journal of Physiology, 250, R721-R727.

Petrowski, K., Herold, U., Joraschky, P., Wittchen, H.U., \& Kirschbaum, C. (2010). A striking pattern of cortisol non-responsiveness to psychosocial stress in patients with panic disorder with concurrent normal cortisol awakening responses. Psychoneuroendocrinology, $35,414-421$.

Pineda, J., \& Aghajanian, G.K. (1997). Carbon dioxide regulates the tonic activity of locus coeruleus neurons by modulating a protonand polyamine-sensitive inward rectifier potassium current. Neuroscience, 77, 723-743.

Pitts, F.N., \& McClure, J.N. (1967). Lactate metabolism in anxiety neurosis. New England Journal of Medicine, 277, 1329-1336.

Pobbe, R.L., \& Zangrossi Jr., H. (2005). 5-HT(1A) and 5-HT(2A) receptors in the rat dorsal periaqueductal gray mediate the antipaniclike effect induced by the stimulation of serotonergic neurons in the dorsal raphe nucleus. Psychopharmacology, 183, 314-321.

Pollack, M.H., Kradin, R., Otto, M.W., Worthington, J., Gould, R., Sabatino, S.A., \& Rosenbaum, J.F. (1996). Prevalence of panic in patients referred for pulmonary function testing at a major medical center, American Journal of Psychiatry, 153, 110-113.

Potokar, J.P., \& Nutt, D.J. (2000). Chest pain: panic attack or heart attack? International Journal of Clinical Practice, 54, 110-114.

Preter, M., \& Klein, D.F. (2008). Panic, suffocation false alarms, separation anxiety and endogenous opioids. Progress in Neuropsychopharmacology and Biological Psychiatry, 32, 603-612.

Preter, M., Lee, S.H., Petkova, E., Vannucci, M., Kim, S., \& Klein, D.F. (2010). Controlled cross-over study in normal subjects of naloxone-preceding-lactate infusions; respiratory and subjective responses: relationship to endogenous opioid system, suffocation false alarm theory and childhood parental loss. Psycholological Medicine, 1-9.

Raff, H., Shinsako, J., Keil, L.C., \& Dallman, M.F. (1983a). Vasopressin, ACTH, and corticosteroids during hypercapnia and graded hypoxia in dogs. American Journal of Physiology, 244, E453-E458.

Raff, H., Shinsako, J., Keil, L.C., \& Dallman, M.F. (1983b). Vasopressin, ACTH, and blood pressure during hypoxia induced at different rates. American Journal of Physiology, 245, E489-E493.

Raff, H., Shinsako, J., \& Dallman, M.F. (1984). Renin and ACTH responses to hypercapnia and hypoxia after chronic carotid chemodenervation. American Journal of Physiology, 247, R412-R417.

Raff, H., Sandri, R.B., \& Segerson, T.P. (1986). Renin, ACTH, and adrenocortical function during hypoxia and hemorrhage in conscious rats. American Journal of Physiology, 250, R240-R244.

Rajan, S., Wischmeyer, E., Xin, L.G., Preisig-Muller, R., Daut, J., Karschin, A., \& Derst, C. (2000). TASK-3, a novel tandem pore domain acid-sensitive $\mathrm{K}+$ channel. An extracellular histiding as $\mathrm{pH}$ sensor. Journal of Biological Chemistry, 275, 16650-16657.

Redgrave, P., \& Dean, P. (1991). Does the PAG learn about emergencies from the superior colliculus? In A. Depaulis and R. Bandler (Eds.), The Midbrain Periaqueductal Gray Matter (pp. 199-209). New York: Plenum Press.

Reiman, E.M., Fusselman, M.J., Fox, P.T., \& Raichle, M.E. (1989a). Neuroanatomical correlates of anticipatory anxiety. Science, 243, 1071-1074.

Reiman, E.M., Raichle, M.E., Robins, E., Mintun, M.A., Fusselman,
M.J., Fox, P. T., Price, J.L., \& Hackman, K.A. (1989). Neuroanatomical correlates of a lactate-induced anxiety attack. Archives in General Psychiatry, 46, 493-500.

Ricardo, J.A., \& Koh, E.T. (1978). Anatomical evidence of direct projections from the nucleus of the solitary tract to the hypothalamus, amygdala and other forebrain structures in the rat. Brain Research, 153, 1-26.

Rifkin, A., Klein, D. F., Dillon, D., \& Levitt, M. (1981). Blockade by imipramine or desipramine of panic induced by sodium lactate. American Journal of Psychiatry, 138, 676-677.

Robichaud, R.C., \& Sledge, K.L. (1969). The effects of p-chlorophenylalanine on experimentally induced conflict in the rat. Life Sciences, 8, 965-969.

Rodgers, R.J., Ishii, Y., Halford, J.C., \& Blundell, J.E. (2002). Orexins and appetite regulation. Neuropeptides, 36, 303-325.

Roseboom, P.H., Nanda, S.A., Bakshi, V.P., Trentani, A., Newman, S.M., \& Kalin, N.H. (2007). Predator threat induces behavioral inhibition, pituitary-adrenal activation and changes in amygdala CRF-binding protein gene expression. Psychoneuroendocrinology, $32,44-55$.

Rosen, J.B. (2004). The neurobiology of conditioned and unconditioned fear: a neurobehavioral system analysis of the amygdala. Behavioral and Cognitive Neuroscience Reviews, 3, 23-41.

Ryan, J.W., \& Waldrop, T.G. (1995). Hypoxia sensitive neurons in the caudal hypothalamus project to the periaqueductal gray. Respiratory Physiology, 100, 185-194.

Sachs, E. (1911). On the relation of the optic thalamus to respiration, circulation, temperature, and the spleen. Journal of Experimental Medicine, 14, 408-440.

Sajdyk, T.J., Schober, D.A., Gehlert, D.R., \& Shekhar, A. (1999). Role of corticotropin-releasing factor and urocortin within the basolateral amygdala of rats in anxiety and panic responses. Behavioral Brain Research, 100, 207-215.

Sajdyk, T.J., \& Shekhar, A. (2000). Sodium lactate elicits anxiety in rats after repeated GABA receptor blockade in the basolateral amygdala. European Journal of Pharmacology, 394, 265-273.

Sandkühler, J. (1991). Induction of the proto-oncogene c-fos as a cellular marker of brainstem neurons activated from the PAG. In A. Depaulis \& R. Bandler (Eds.), The Midbrain Periaqueductal Gray Matter. Functional, Anatomical and Neurochemical Organization (pp. 267-286). New York: Plenum Press.

Sandkuhler, J., \& Herdegen, T. (1995). Distinct patterns of activated neurons throughout the rat midbrain periaqueductal gray induced by chemical stimulation within its subdivisions. Journal of Comparative Neurology, 357, 546-553.

Sasson, Y., Iancu, I., Fux, M., Taub, M., Dannon, P.N., \& Zohar, J. (1999). A double-blind crossover comparison of clomipramine and desipramine in the treatment of panic disorder. European Neuropsychopharmacolology, 9, 191-196.

Sato, M., Severinghaus, J.W., \& Basbaum, A.I. (1992). Medullary CO2 chemoreceptorneuronidentification by c-fos immunocytochemistry. Journal of Applied Physiology, 73, 96-100.

Schenberg, L.C., \& Graeff, F.G. (1978). Role of the periaqueductal gray substance in the antianxiety action of benzodiazepines. Pharmacology, Biochemistry and Behavior, 9, 287-295.

Schenberg, L.C., de Aguiar, J.C., Salgado, H.C., \& Graeff, F.G. (1981). Depressant action of chlordiazepoxide on cardiovascular and respiratory changes induced by aversive electrical stimulation of the brain. Brazilian Journal of Medical and Biological Research, 14, 69-72.

Schenberg, L.C., de Aguiar, J.C., \& Graeff, F.G. (1983). GABA modulation of the defense reaction induced by brain electrical stimulation. Physiology and Behavior, 31, 429-437.

Schenberg, L.C., Costa, M.B., Borges, P.C.L., \& Castro, M.F.S. (1990). Logistic analysis of the defense reaction induced by electrical stimulation of the rat mesencephalic tectum. Neuroscience and Biobehavioral Reviews, 14, 473-479.

Schenberg, L.C., Bittencourt, A.S., Sudré, E.C.M., \& Vargas, L.C. (2001). Modeling panic attacks. Neuroscience and Biobehavioral Reviews, 25, 647-659.

Schenberg, L.C., Capucho, L.B., Vatanabe, R.O., \& Vargas, L.C. (2002). Acute effects of clomipramine and fluoxetine on dorsal periaqueductal grey-evoked unconditioned defensive behaviours of the rat. Psychopharmacology, 159, 138-144.

Schenberg, L.C., Póvoa, R.M.F., Costa, A.L., Caldellas, A.V., Tufik, S., \& Bittencourt, A.S. (2005). Functional specializations within the 
tectum defense systems of the rat. Neuroscience and Biobehavioral Reviews, 29, 1279-1298.

Schenberg, L.C., Dos Reis, A.M., Ferreira Povoa, R.M., Tufik, S., \& Silva, S.R. (2008). A panic attack-like unusual stress reaction. Hormones and Behavior, 54, 584-591.

Schimitel, F.G. (2009). Effects of carbon dioxide and potassium cyanide on the thresholds of defensive responses induced by electrical stimulation of the dorsal periaqueductal gray matter. Master Degree Thesis, Federal University of Espírito Santo, Vitória, Brazil.

Schlaefke, M.E. (1981). Central chemosensitivity: a respiratory drive. Reviews of Physiology, Biochemistry and Pharmacology, 90, 171-244.

Schmitt, P., Carrive, P., Di Scala, S.G., Jenck, F., Brandão, M., Bagri, A., Moreau, J.L., \& Sandner, G. (1986). A neuropharmacological study of the periventricular neural substrate involved in flight. Behavioral Brain Research, 22, 181-190.

Schneier, F.R., Liebowitz, M.R., Davies, S.O., Fairbanks, J., Hollander, E., \& Campeas, R. (1990). Fluoxetine in panic disorder. Journal of Clinical Psychopharmacology, 10, 119-121.

Seedat, S., van Rheede van Oudtshorn, E., Muller, J.E., Mohr, N., \& Stein, D.J. (2003). Reboxetine and citalopram in panic disorder: a single-blind, cross-over, flexible-dose pilot study. International Clinical Psychopharmacology, 18, 279-284.

Selden, N.R., Everitt, B.J., Jarrard, L.E., \& Robbins, T.W. (1991). Complementary roles for the amygdala and hippocampus in aversive conditioning to explicit and contextual cues. Neuroscience, $42,335-350$.

Selye, H. (1936). A syndrome produced by diverse nocuous agents. Nature, 138,32 .

Selye, H. (1956). The Stress of Life. New York: McGraw-Hill.

Selye, H. (1976). Forty years of stress research: principal remaining problems and misconceptions. Cananadian Medical Association Journal, 115, 53-56.

Sepinwall, J., \& Grodsky, F.S. (1969). Effects of cholinergic stimulation or blockade of the rat hypothalamus on discrete-trial conflict behavior. Life Sciences, 8, 45-52.

Servan-Schreiber, D., Printz, H., \& Cohen, J.D. (1990). A network model of catecholamine effects: gain, signal-to-noise ratio, and behavior. Science, 249, 892-895.

Shams, I., Avivi, A., \& Nevo, E. (2005). Oxygen and carbon dioxide fluctuations in burrows of subterranean blind mole rats indicate tolerance to hypoxic-hypercapnic stresses. Comparative Biochemistry and Physiology Part A: Molecular \& Integrative Physiology, 142, 376-382.

Shavitt, R.G., Gentil, V., \& Mandetta, R. (1992). The association of panic/agoraphobia and asthma. Contributing factors and clinical implications. General Hospital Psychiatry, 14, 420-423.

Shekhar, A. (1993). GABA receptors in the region of the dorsomedial hypothalamus of rats regulate anxiety in the elevated plus-maze test. I. Behavioral measures. Brain Research, 627, 9-16.

Shekhar, A. (1994). Effects of treatment with imipramine and clonazepam on an animal model of panic disorder. Biological Psychiatry, 36, 748-758.

Shekhar, A., \& DiMicco, J.A. (1987). Defense reaction elicited by injection of GABA antagonists and synthesis inhibitors into the posterior hypothalamus in rats. Neuropharmacology, 26, 407-417.

Shekhar, A., \& DiMicco, J.A. (1987). Defense reaction elicited by injection of GABA antagonists and synthesis inhibitors into the posterior hypothalamus in rats. Neuropharmacology, 26, 407-417.

Shekhar, A., \& Keim, S.R. (2000). LY354740, a potent group II metabotropic glutamate receptor agonist prevents lactate-induced panic-like response in panic-prone rats. Neuropharmacology, 39, 1139-1146.

Shekhar, A., Hingtgen, J.N., \& DiMicco, J.A. (1987). Selective enhancement of shock avoidance responding elicited by GABA blockade in the posterior hypothalamus of rats. Brain Research, 420, 118-128.

Shekhar, A., Hingtgen, J.N., \& DiMicco, J.A. (1990). GABA receptors in the posterior hypothalamus regulate experimental anxiety in rats. Brain Research, 512, 81-88.

Shekhar, A. (1993). GABA receptors in the region of the dorsomedial hypothalamus of rats regulate anxiety in the elevated plus-maze test. I. Behavioral measures. Brain Research, 627, 9-16.

Shekhar, A., Keim, S.R., Simon, J.R., \& McBride, W.J. (1996). Dorsomedial hypothalamic GABA dysfunction produces physiological arousal following sodium lactate infusions.
Pharmacology Biochememistry and Behavior, 55, 249-256.

Shekhar, A., Sajdyk, T.S., Keim, S.R., Yoder, K.K., \& Sanders, S.K. (1999). Role of the basolateral amygdala in panic disorder. Annals of the New York Academy of Sciences, 877, 747-750.

Shlik, J., Aluoja, A., Vasar, V., Vasar, E., Podar, T., \& Bradwejn, J. (1997). Effects of citalopram treatment on behavioural, cardiovascular and neuroendocrine response to cholecystokinin tetrapeptide challenge in patients with panic disorder. Journal of Psychiatry \& Neuroscience, 22, 332-340.

Siegel, R.A., Conforti, N., \& Chowers, I. (1980). Neural pathways mediating the prolactin secretory response to acute neurogenic stress in the male rat. Brain Research, 198, 43-53

Simon, H., Le Moal, M., \& Cardo, B. (1976). Intracranial selfstimulation from the dorsal raphe nucleus of the rat: effects of the injection of para-chlorophenylalanine and of alphamethylparatyrosine. Behavioral Biology, 16, 353-364.

Sinha, S.S., Coplan, J.D., Pine, D.S., Martinez, J.A., Klein, D.F., \& Gorman, J.M. (1999). Panic induced by carbon dioxide inhalation and lack of hypothalamic-pituitary-adrenal axis activation. Psychiatry Research, 86, 93-98.

Siqueira, C.C., Rossoni, R.R., \& Schenberg, L.C. (2010). Dorsal periaqueductal gray matter-evoked panic-like behaviors are markedly inhibited by a low peripheral dose of thyrotropin releasing hormone. Psychoneuroendocrinology, 35, 262-271.

Siqueira, C.C., Rossoni, R.R., Tiengo, A.N., Tufik, S., \& Schenberg, L.C. (2010). Methimazole-induced hypothyroidism inhibits the panic-like behaviors produced by electrical stimulation of dorsal periaqueductal gray matter of rats. Psychoneuroendocrinology, 35, 706-716.

Smith, S.S. (2002). Withdrawal properties of a neuroactive steroid: implications for $\mathrm{GABA}(\mathrm{A})$ receptor gene regulation in the brain and anxiety behavior. Steroids, 67, 519-528.

Smith, S.S., \& Woolley, C.S. (2004). Cellular and molecular effects of steroid hormones on CNS excitability. Cleveland Clinics Journal of Medicine, 71, S4-S10

Smith, S.S., Gong, Q.H., Hsu, F.C., Markowitz, R.S., FfrenchMullen, J.M., \& Li, X. (1998). GABA(A) receptor alpha4 subunit suppression prevents withdrawal properties of an endogenous steroid. Nature, 392, 926-930.

Smith, W.K. (1950). Non-olfatory functions of the pyriform-amydaloidhippocampal complex. Federation Proceedings, 9, 118.

Srebro, B., \& Lorens, S.A. (1975). Behavioral effects of selective midbrain raphe lesions in the rat. Brain Research, 89, 303-305.

Stezhka, V.V., \& Lovick, T.A. (1994). Influence of the dorsal raphe nucleus on neurones in the midbrain defense area of the rat: electrophysiological and anterograde tracing studies in vitro. Journal of Physiology, 476, 46.

Strohle, A., \& Holsboer, F. (2003). Stress responsive neurohormones in depression and anxiety. Pharmacopsychiatry, 36, S207-214.

Subramanian, H.H., Balnave, R.J., \& Holstege, G. (2008). The midbrain periaqueductal gray control of respiration. Journal of Neuroscience, 28, 12274-12283.

Taheri, S., Zeitzer, J.M., \& Mignot, E. (2002). The role of hypocretins (orexins) in sleep regulation and narcolepsy. Annual Review in Neuroscience, 25, 283-313.

Talley, E.M., Solorzano, G., Lei, Q., Kim, D., \& Bayliss, D.A. (2001). CNS distribution of members of the two-pore-domain (KCNK) potassium channel family. Journal of Neuroscience, 21, 7491-7505.

Tannure, R.M., Bittencourt, A.S., \& Schenberg, L.C. (2009). Short-term full kindling of the amygdala dissociates natural and periaqueductal gray-evoked flight behaviors of the rat. Behavioral Brain Research, 199, 247-256.

Taylor, K.M., \& Laverty, R. (1969). The effect of chlordiazepoxide, diazepam and nitrazepam on catecholamine metabolism in regions of the rat brain. European Journal of Pharmacology, 8, 296-301.

Teppema, L.J., Veening, J.G., Kranenburg, A., Dahan, A., Berkenbosch, A., \& Olievier, C. (1997). Expression of c-fos in the rat brainstem after exposure to hypoxia and to normoxic and hyperoxic hypercapnia. Journal of Comparative Neurolology, 388, $169-190$

Ter Horst, G.J., \& Luiten, P.G. (1986). The projections of the dorsomedial hypothalamic nucleus in the rat. Brain Research Bulletin, 16, 231-248

Thompson, A.F., \& Walker, A.E. (1951). Behavioral alterations following lesions of the medial surface of the temporal lobe. Archives of Neurogical Psychiatry, 65, 251-252. 
Tischler, M.D., \& Davis, M. (1983). A visual pathway that mediates fear-conditioned enhancement of acoustic startle. Brain Research, 276, 55-71.

Ursin, H. (1965). The effect of amygdaloid lesions on flight and defense behavior in cats. Experimental Neurology, 11, 61-79

Ursin, H., \& Kaada, B.R. (1960). Subcortical structures mediating the attention response induced by amygdala stimulation. Experimental Neurology, 2, 109-122.

van Duinen, M.A., Schruers, K.R., Maes, M., \& Griez, E.J. (2005). CO2 challenge results in hypothalamic-pituitary-adrenal activation in healthy volunteers. Journal of Psychopharmacology, 19, 243-247.

van Duinen, M.A., Schruers, K.R., Maes, M., \& Griez, E.J. (2007). $\mathrm{CO} 2$ challenge induced HPA axis activation in panic. International Journal of Neuropsychopharmacology, 10, 797-804.

Vargas, L.C. (2002). Modeling panic attacks: Psychopharmacology of innate defensive behaviors induced by electrical stimulation of the dorsal periaqueductal gray matter. Doctoral Thesis, Federal University of Espírito Santo, Vitória, Brazil.

Vargas, L.C., \& Schenberg, L.C. (2001). Long-term effects of clomipramine and fluoxetine on dorsal periaqueductal grey-evoked innate defensive behaviours of the rat. Psychopharmacology, 155, 260-268.

Versiani, M., Cassano, G., Perugi, G., Benedetti, A., Mastalli, L., Nardi, A., \& Savino, M. (2002). Reboxetine, a selective norepinephrine reuptake inhibitor, is an effective and well-tolerated treatment for panic disorder. Journal of Clinical Psychiatry, 63, 31-37.

Vianna, D.M., Graeff, F.G., Landeira-Fernandez, J., \& Brandão, M.L. (2001). Lesion of the ventral periaqueductal gray reduces conditioned fear but does not change freezing induced by stimulation of the dorsal periaqueductal gray. Learning and Memory, 8, 164-169.

Walker, A.E., Thompson, A.F., \& McQueen, J.D. (1953). Behavior and the temporal rhinencephalon in the monkey. Bulletin of Johns Hopkins Hospital, 93, 65-93.

Walker, D.L., \& Davis, M. (1997). Double dissociation between the involvement of the bed nucleus of the stria terminalis and the central nucleus of the amygdala in startle increases produced by conditioned versus unconditioned fear. Journal of Neuroscience, 17, 9375-9383.

Washburn, C.P., Sirois, J.E., Talley, E.M., Guyenet, P.G., \& Bayliss, D.A. (2002). Serotonergic raphe neurons express TASK channel transcripts and a TASK-like $\mathrm{pH}$ - and halothane-sensitive $\mathrm{K}+$ conductance. Journal of Neuroscience, 22, 1256-1265.

Washburn, C.P., Bayliss, D.A., \& Guyenet, P.G. (2003).
Cardiorespiratory neurons of the rat ventrolateral medulla contain TASK-1 and TASK-3 channel mRNA. Respiratory Physiology and Neurobiology, 138, 19-35.

Westenberg, H.G.M., \& Den Boer, J.A. (1993). Serotonegic basis of panic disorder. In S.A. Montgomery (Ed.), Psychopharmacology of Panic (pp. 91-109). Oxford: Oxford University Press.

Wilent, W.B., Oh, M.Y., Buetefisch, C.M., Bailes, J.E., Cantella, D., et al. (2010). Induction of panic attack by stimulation of the ventromedial hypothalamus. Journal of Neurosurgery, 112, 1295-1298.

Wise, C.D., Berger, B.D., \& Stein, L. (1970). Serotonin: a possible mediator of behavioral suppression induced by anxiety. Diseases of Nervous System, 31, S34-S37.

Wise, C.D., Berger, B.D., \& Stein, L. (1972). Benzodiazepines: anxiety-reducing activity by reduction of serotonin turnover in the brain. Science, 177, 180-183.

Wise, C.D., Berger, B.D., \& Stein, L. (1973). Evidence of a-noradrenergic reward receptors and serotonergic punishment receptors in the rat brain. Biological Psychiatry, 6, 3-21.

Woods, S.W., Charney, D.S., McPherson, C.A., Gradman, A.H., \& Heninger, G.R. (1987). Situational panic attacks. Behavioral, physiologic, and biochemical characterization. Archives of General Psychiatry, 44, 365-375.

Woods, S.W., Charney, D.S., Goodman, W.K., \& Heninger, G.R. (1988). Carbon dioxide-induced anxiety. Behavioral, physiologic, and biochemical effects of carbon dioxide in patients with panic disorders and healthy subjects. Archives of General Psychiatry, 45, 43-52.

Woods, S.W., Charney, D.S., Delgado, P.L., \& Heninger, G.R. (1990). The effect of long-term imipramine treatment on carbon dioxideinduced anxiety in panic disorder patients. Journal of Clinical Psychiatry, 51, 505-507.

Yeragani, V.K., Pohl, R., Balon, R., Rainey, J.M., Berchou, R., \& Ortiz, A. (1988). Sodium lactate infusion after treatment with tricyclic antidepressants: behavioral and physiological findings. Biological Psychiatry, 24, 767-774.

Yonkers, K.A., Pearlstein, T., \& Rosenheck, R.A. (2003). Premenstrual disorders: bridging research and clinical reality. Archives of Women's Mental Health, 6, 287-292.

Zaretskaia, M.V., Zaretsky, D.V., Shekhar, A., \& DiMicco, J.A. (2002). Chemical stimulation of the dorsomedial hypothalamus evokes non-shivering thermogenesis in anesthetized rats. Brain Research, 928, 113-125.

Zhang, W., Hayward, L.F., \& Davenport, P.W. (2007). Respiratory responses elicited by rostral versus caudal dorsal periaqueductal gray stimulation in rats. Autonomic Neuroscience, 134, 45-54.. 